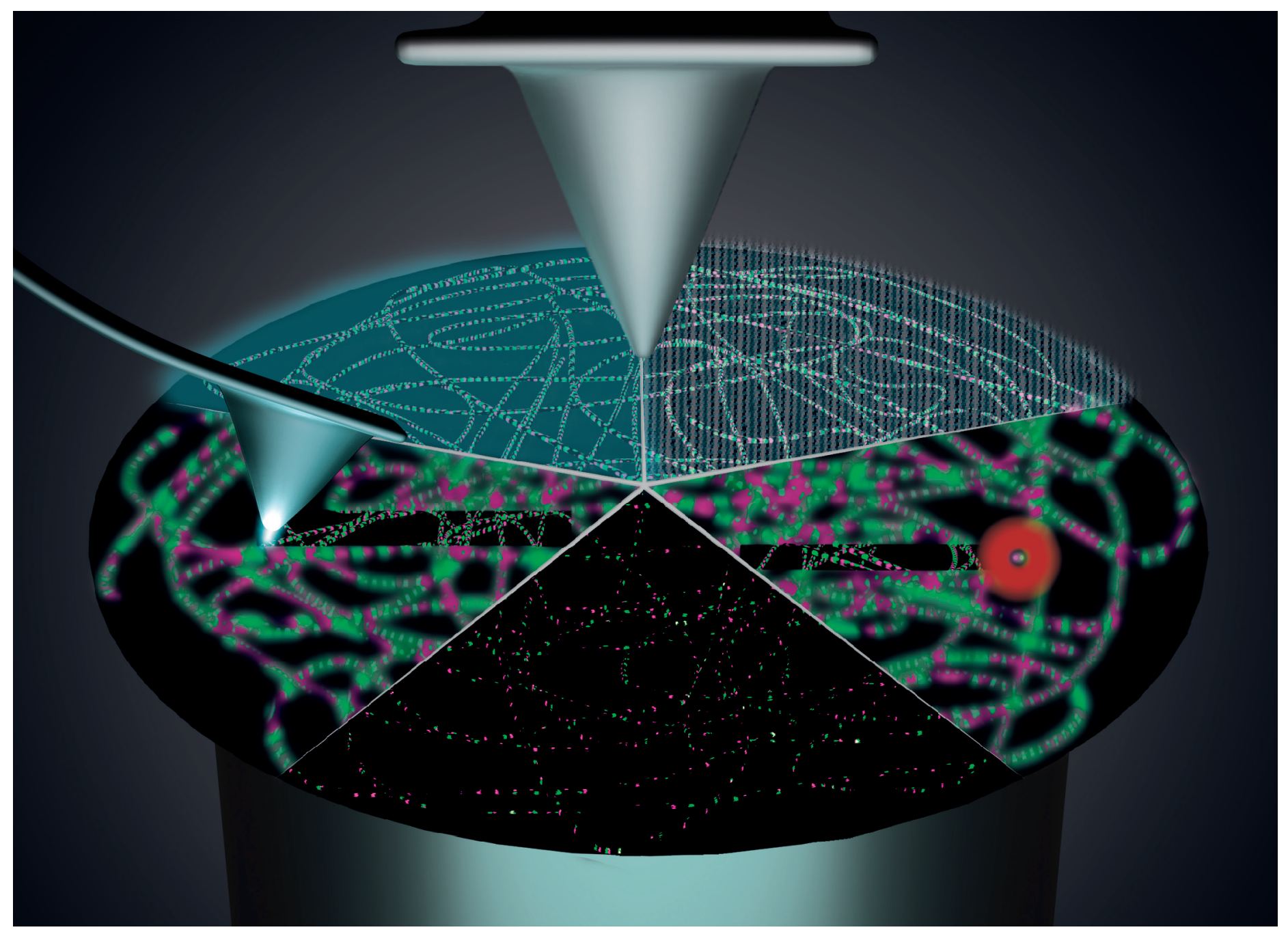

Showcasing a collaborative review work between the laboratory of Dr Pieter De Beule with Dr Andreas Stylianou, Dr Liisa Hirvonen and Dr Humberto Sánchez.

How did correlative atomic force microscopy and superresolution microscopy evolve in the quest for unravelling enigmas in biology?

The correlation of AFM with optical microscopy techniques is a highly effective approach to obtain complementary information from a biological system. The gap in resolution between AFM and conventional optical microscopy has been closed by recent advances in super-resolution fluorescence imaging. In this research article, we provide a comprehensive picture on the different combined AFM and super-resolution fluorescence microscopy systems and how they can be applied for expanding our knowledge on biological processes.

\section{As featured in:}

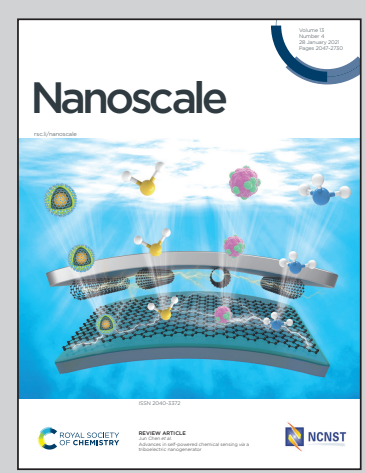

See Ana I. Gómez-Varela,

Pieter A. A. De Beule et al., Nanoscale, 2021, 13, 2082. 


\section{A) Check for updates}

Cite this: Nanoscale, 2021, 13, 2082

\title{
How did correlative atomic force microscopy and super-resolution microscopy evolve in the quest for unravelling enigmas in biology?
}

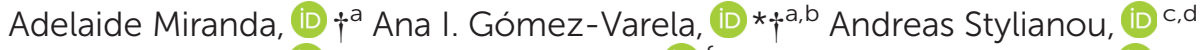

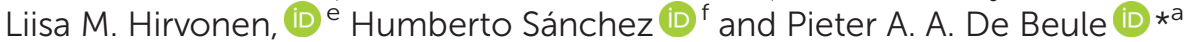

\begin{abstract}
With the invention of the Atomic Force Microscope (AFM) in 1986 and the subsequent developments in liquid imaging and cellular imaging it became possible to study the topography of cellular specimens under nearly physiological conditions with nanometric resolution. The application of AFM to biological research was further expanded with the technological advances in imaging modes where topographical data can be combined with nanomechanical measurements, offering the possibility to retrieve the biophysical properties of tissues, cells, fibrous components and biomolecules. Meanwhile, the quest for breaking the Abbe diffraction limit restricting microscopic resolution led to the development of super-resolution fluorescence microscopy techniques that brought the resolution of the light microscope comparable to the resolution obtained by AFM. The instrumental combination of AFM and optical microscopy techniques has evolved over the last decades from integration of AFM with bright-field and phase-contrast imaging techniques at first to correlative AFM and wide-field fluorescence systems and then further to the combination of AFM and fluorescence based super-resolution microscopy modalities. Motivated by the many developments made over the last decade, we provide here a review on AFM combined with super-resolution fluorescence microscopy techniques and how they can be applied for expanding our understanding of biological processes.
\end{abstract}

Received 8th October 2020 Accepted 26th November 2020 DOI: $10.1039 /$ dOnr07203f rsc.li/nanoscale ticity, viscosity and adhesion. ${ }^{14-16}$ The first imaging mode used in AFM was the so-called contact mode, but nowadays a myriad of modes ${ }^{17}$ are available to image the diverse and complex biological specimens: dynamic, force-distance curvebased, multiparametric, molecular recognition and multifrequency. Technological developments ${ }^{18}$ have paved the way to high-speed AFM (HS-AFM) where the image acquisition speed can be increased by a factor of approximately 1000 compared to conventional imaging. ${ }^{19}$ This enables the measurement of dynamic behaviour in many biological processes, e.g. biomolecules, ${ }^{19-24}$ live bacteria ${ }^{25,26}$ and eukaryotic cells, ${ }^{27}$ which cannot be achieved with conventional AFM. Both AFM and HS-AFM have found extensive applications in the biological field. ${ }^{15,28-38}$

The main drawback of AFM is that imaging is limited to the sample surface. Hence, the advantages of combining microscopy approaches were soon realised. ${ }^{39,40}$ The possibility of retrieving physical, chemical and biological information in complex systems using correlative microscopy methods set the stage for the emergence of hybrid systems. ${ }^{41,42}$ Over the past two decades AFM has been combined with electron microscopy, ${ }^{43,44}$ confocal Raman microspectroscopy ${ }^{45}$ and optical $^{46-48}$ and fluorescence microscopy techniques. Fluorescence microscopy is a popular imaging technique 
especially in the biological sciences field, where it allows the tagging of intracellular molecules and cellular components with high specificity, and their observation inside cells in a minimally invasive manner using non-destructive wavelengths of light in the visible spectrum. ${ }^{49}$ AFM has been combined with confocal laser scanning microscopy, ${ }^{50-57}$ fast $^{58}$ and differential spinning disks, ${ }^{59,60}$ and volumetric light sheet microscopy, ${ }^{61-63}$ as well as some specialised fluorescence characterisation techniques, e.g. Förster Resonance Energy Transfer (FRET), ${ }^{64}$ Fluorescence Lifetime Imaging (FLIM), ${ }^{65}$ and Fluorescence Correlation Spectroscopy (FCS). ${ }^{66}$ Although many biologically oriented AFM systems, the so-called BioAFMs, include an optical microscope coupled to the AFM, the correlation of these techniques is complicated by the diffraction limit of light restricting the resolution in optical microscopy to two orders of magnitude more than AFM.

The development of super-resolution microscopy techniques has brought the resolution of light microscopy down by approximately an order of magnitude, similar to the typical lateral resolution achieved with AFM when imaging soft biological samples. In the 1990s, at the same time as the first AFM results emerged in the biological field, the optical microscopy field was in a quest of going beyond the Abbe diffraction limit, ${ }^{67}$ which would allow an optical microscope to resolve structures separated by less than approximately $200 \mathrm{~nm}$ in the lateral dimension. This would lead to the development of Super-Resolution (SR) fluorescence microscopy techniques, ${ }^{68-70}$ first as theoretical concepts and then as experimental techniques in both far-field and near-field. This concept of super-resolution was introduced by Giuliano Toraldo di Francia. ${ }^{71,72}$ In his 1955 paper he defined superresolution as the discrimination of details below the Abbe resolution limit. ${ }^{72}$ Toraldo di Francia proposed an original approach to overcome the diffraction barrier, showing in a theoretical study that with finely tuned pupil filters a precisely tailored sub-diffracted spot can be produced. In 1994, Stefan Hell and Jan Wichmann's theoretical work showed, for the first time since Abbe formulated the diffraction limit 180 years ago, that it was possible to image beyond the diffraction limit in the optical far-field. ${ }^{73}$ With this new concept, referred to as STimulated Emission Depletion (STED), Stefan Hell opened the far-field microscopy field to the nanometric spatial resolution $^{74,75}$ and was one of the three winners of the Nobel Prize in Chemistry in 2014 that was awarded for the development of super-resolution microscopy techniques.

Soon afterwards, other techniques were developed that could also reach resolution beyond Abbe's limit. Gustafsson et al. (2000) were the first to experimentally verify lateral resolution enhancement beyond the diffraction limit using Super-Resolution Structured Illumination Microscopy (SR-SIM), ${ }^{76}$ and in 2006, yet another class of SR techniques were demonstrated, based on single-molecule localisation microscopy (SMLM). SMLM was first described theoretically by Eric Betzig in $1995,{ }^{77}$ a study that contributed to the award of the 2014 Nobel prize in Chemistry jointly with Stefan Hell and W. E. Moerner, and 10 years later Xiaowei Zhuang's group, ${ }^{78}$
Eric Betzig and Harald Hess, ${ }^{79}$ and Michael Mason's group ${ }^{80}$ presented similar practical solutions on how to resolve single fluorescent molecules in a highly populated sample: Stochastic Optical Reconstruction Microscopy (STORM), Photo-Activated Light Microscopy (PALM), and Fluorescence PALM (FPALM), respectively.

In the past decade, these far-field SR methods have become popular imaging techniques in biological research, and commercial instruments are now widely available. All of these SR microscopy techniques have been combined with AFM: ${ }^{81,82}$ the combination of STED and AFM was first reported by Chacko et al. in 2012, ${ }^{83}$ STORM and PALM were combined with AFM in $2013^{84,85}$ and $2015,{ }^{86}$ respectively, and recently, in 2020, GómezVarela et al. presented a hybrid system combining SR-SIM and AFM for simultaneous co-localized operation of both systems. ${ }^{87}$

Subwavelength resolution and imaging can also be achieved by placing the sample in the near-field of the illumination or by probing the near-field radiation emitted from a specimen; these techniques are termed Total Internal Reflection Fluorescence Microscopy (TIRFM) and Scanning Near-Field Optical Microscopy (SNOM/NSOM), respectively. Imaging platforms based on combined TIRFM and AFM have been demonstrated over the years for a variety of biological applications, e.g., lipid bilayer dynamics and cellular dynamics and structures, among others. ${ }^{88}$ SNOM also takes advantage of the confinement of radiation fields for resolution enhancement and has been integrated with both AFM and HS-AFM. ${ }^{89,90}$

These impressive advances in SR optical microscopy have helped bridge the gap between the resolution achievable in optical microscopy and AFM, and significantly enrich the toolbox available for biological system characterisation. The variety of hybrid systems and key accomplishments that have been made in this field over the years are summarized in Fig. 1.

In this review, we provide an overview of how correlative AFM and SR fluorescence microscopy techniques in both farfield and near-field have developed in the context of biological applications. In the far-field we review the combination of AFM with SMLM, STED, and SR-SIM microscopy techniques, and in the near-field we describe the combination of AFM with TIRFM and SNOM. After a general introduction to AFM, a brief overview of the main principles of each SR technique is given in the sections dedicated to these techniques, followed by examples of biological applications using the combined SR and AFM system. Different combined AFM/SR techniques are compared in a dedicated section, and finally, we discuss the future perspectives of combining AFM with SR fluorescence microscopy techniques in the quest for answers in the field of biology.

\section{Atomic force microscopy background}

\subsection{Physical principles}

AFM operation is based on the interactions of an AFM probe with the specimen surface. The AFM probe is usually a nano- 


\section{Some key developments in combined AFM and Super-Resolution optical schemes}

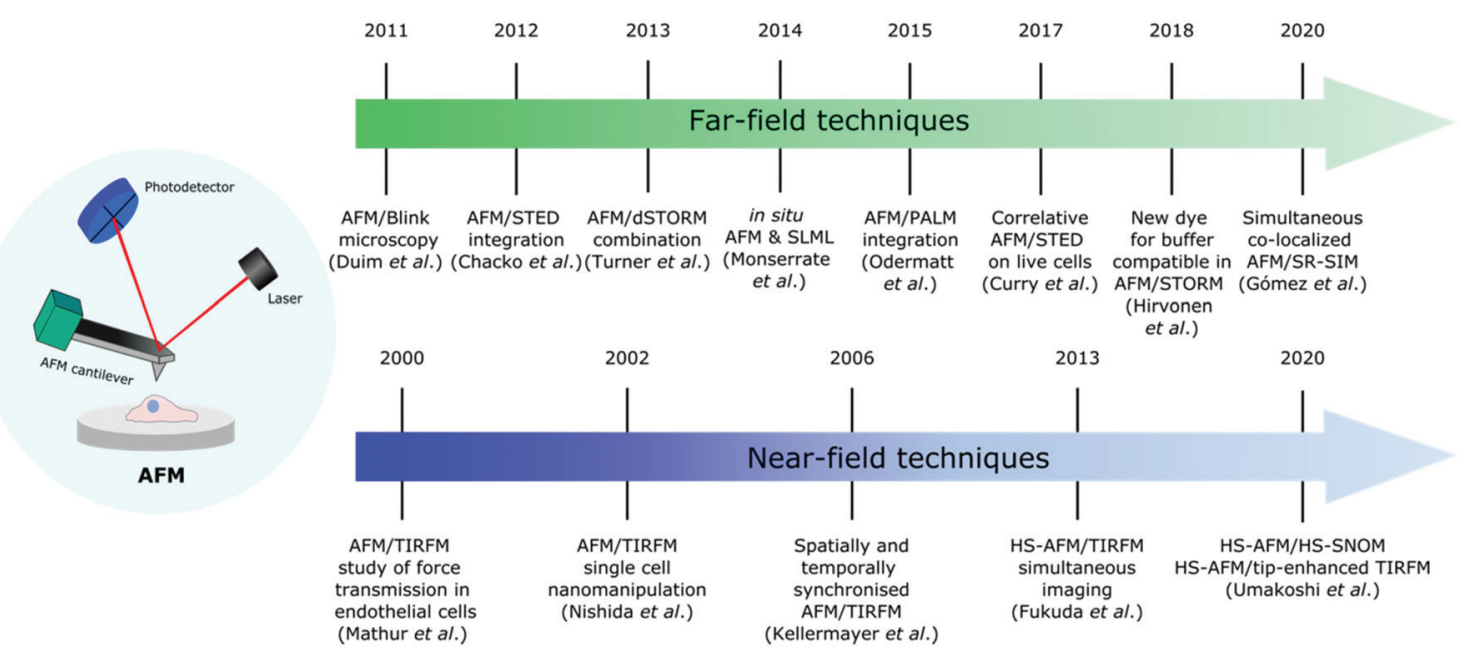

Fig. 1 Timeline showing some major advances in the development of different far-field and near-field SR techniques combined with AFM for life science applications.

meter-sized tip mounted on the free end of a cantilever, which is a flat spring. Depending on the application, different tips can be used ranging from sharp nanoscale tips to ball-shaped tips with a diameter of several micrometers. Cantilevers also come in many shapes and sizes; the more popular ones are beam-like and V-shaped cantilevers. Cantilevers are characterized by their resonance frequency and spring constants, which range from few kilohertz $(\mathrm{kHz})$ up to $\mathrm{MHz}$ and from $0.01 \mathrm{~N}$ $\mathrm{m}^{-1}$ to several hundred $\mathrm{N} \mathrm{m}^{-1}$, respectively. During AFM operation, the AFM probe scans the specimen surface line by line in a grid pattern. Accurate movement of either the AFM probe or the sample stage, depending on the design, is achieved by piezoelectric scanners. Due to the forces acting between the tip and the sample surface, the cantilever bends. The cantilever movement and bending are measured with an optical system, where a laser beam is reflected from the back of the cantilever and directed to a four-quadrant position-sensitive photodetector. The photodetector records the position of the laser, which is then converted into lateral and vertical deflection signals. Considering the cantilever spring constant and the photodetector sensitivity, these signals are then converted into a force for each pixel, and a digital pseudo-colored image of the specimen surface can be built. The development of the optical detection system and the fluid cell that enables AFM to operate in aqueous solution led to the first Bio-AFM and was a significant milestone in the history of AFM technology. ${ }^{3,4,17}$

\subsection{Typical set-up and modes}

AFM systems can operate in a number of different modes. ${ }^{17}$ The most widely used modes for topography imaging are the contact, intermittent and non-contact modes. In the noncontact mode, the tip does not encounter the sample surface, while in the contact mode the tip is always in contact with the sample surface. In the dynamic or intermittent mode, also known as tapping, AC or oscillation mode, the tip taps the sample surface, touching the surface only for a short time. In this mode the cantilever oscillates at or near its resonant frequency, thus minimizing the energy in the tip-sample system, and the friction. A number of other dynamic modes have also been developed, which take into account different signals as feedback parameters, or excite the cantilever at different frequencies (multifrequency imaging). ${ }^{17,91-93}$ In biological applications silicon nitride cantilevers are often used, with an aluminium or gold coating on the back surface to improve the reflection of the laser beam under liquid conditions. For imaging biological samples the tapping mode is widely used as it is less destructive than the contact mode, and issues with lateral and frictional forces, which are observed in the noncontact mode, are minimized. ${ }^{94,95}$

Besides surface imaging, AFM can operate in the force spectroscopy mode. ${ }^{96}$ In this mode, force curves representing the force versus tip-sample distance are recorded at a specific location. ${ }^{97} \mathrm{~A}$ calibration procedure including deflection sensitivity calibration and spring constant calibration is typically required to obtain quantitative data. ${ }^{98,99}$ Although initially it was possible to record only Force-Distance (FD) curves at a single spatial location, nowadays AFMs can collect force curves for a given grid whereby the cantilever scans a specific area of the sample's surface; this mode is called the force-volume mode or FD curve-based imaging mode. ${ }^{35}$ Recent advances, including optimization of hardware control and cantilevers, have enabled the development of fast force spectroscopy and parallel characterization of topographical, mechanical, and chemical characteristics of the sample. Force curves are recorded pixel-by-pixel on well-defined grids, which can achieve the same resolution as conventional imaging modes. Force measurements (force-spectroscopy, force-volume mode, etc.) can provide a vast amount of information on the nanome- 
chanical and biophysical properties of the specimen, such as mechanical properties of living cells including the Young's modulus and interaction forces in various biological systems, e.g., cell-cell adhesion and protein unfolding. AFM-based techniques are not only appropriate for imaging and characterizing complex biological systems, but they are also highly effective for the design of novel biointerfaces. ${ }^{98,100}$

AFM is emerging as a unique tool and nanoscopic platform in the mechanobiology field. However, the measurement of the mechanical properties of complex biological systems at the nanoscale is not trivial, and a number of parameters and issues have to be taken into account, including the appropriate cantilever and probe, the mechanical model (e.g. Hertz/ Sneddon), the environmental conditions and the AFM parameters such as the loading rate. ${ }^{16,101,102}$

Besides the characterization of a sample, AFM can also be used as a nano-manipulation tool either for the mechanical manipulation of the sample by using the tip-sample interactions, or by using a chemically functionalized AFM tip to manipulate targeted specimen regions. ${ }^{17,103}$ The AFM probe can be applied for cutting, picking up and pasting biomolecules. $^{104}$

\section{AFM and far-field super-resolution microscopy techniques}

This section describes the combination of AFM and SR farfield techniques and is divided into three main parts: singlemolecule localisation microscopy techniques, STED and SR-SIM. Each section describes the principles of the SR technique, and the applications of the combined AFM-SR system.

\subsection{Single-molecule localisation microscopy (SMLM)}

a. SMLM technical features. Single-molecule localisation microscopy techniques offer theoretically unlimited resolution which, in reality, is limited by the signal-to-noise ratio typically to a few tens of nanometres. With SMLM techniques, the fluorophores are switched on and off between frames such that only a small subset emits fluorescence in each frame. Many images of the sample are then collected, in each of which only a few fluorophores are emitting light. While the images of the fluorophores are diffraction limited, their centroid positions can be calculated with great accuracy, and the final super-resolved image is constructed by summing thousands of frames of these localisations together.

The first result on single molecule localisation microscopy was achieved by Yildiz et al. in 2003 to obtain super-resolution images of myosin. ${ }^{105}$ This technique was named Fluorescence Imaging with One Nanometer Accuracy (FIONA), and the super-resolved images were achieved by distributing the fluorescently labelled myosin molecules sparsely over the sample such that the diffraction-limited image of each molecule did not overlap with the images of the other molecules. It was then possible to calculate the centre position of each probe from the diffraction-limited image with great accuracy.
FIONA only works with a sample where the fluorescent labels are very sparsely distributed, and therefore has limited use in imaging biological specimens. In 2006 Xiaowei Zhuang's group ${ }^{78}$ presented a new strategy based on the photoswitching properties of fluorescent cyanine dyes. These dyes can switch between a fluorescent state and a dark state by light activation. The researchers used a low activation light intensity to switch on a small subset of the probes in the sample, took an image of these molecules, and then calculated their centre position. By illuminating the sample with another wavelength of light, this subset of probes was turned off and another subset was turned on. This procedure was iterated many times, until enough positions of molecules were collected to form a high-resolution image of the underlying structure. This method, termed STORM, can achieve a typical lateral resolution of 20 to $30 \mathrm{~nm}$. PALM, published by Betzig and Hess also in $2006,{ }^{79}$ is based on the same principle, but uses photoswitchable fluorescent proteins instead of dyes.

Many other variants of SMLM have been published over the years. In 2008, Heilemann et al. introduced direct STORM (dSTORM), ${ }^{106}$ which simplified the experimental method by using conventional cyanine dyes (Cy5 and Alexa647) and making them blink by the addition of a switching buffer containing a thiol and an oxygen scavenging system (often glucose oxidase (GLOX)) instead of relying on the proximity of two fluorophores attached to an antibody in a specific ratio and at a specific distance. Furthermore, blink microscopy was presented in 2011 ${ }^{107-109}$ widening the pool of fluorescent labels available for SMLM. The point accumulation for imaging in nanoscale topography (PAINT) $\operatorname{method}^{110,111}$ on the other hand achieves the on/off switching behaviour by using freely diffusing dyes that only become fluorescent when they are transiently bound to the target structure.

b. Correlative AFM and SMLM. FIONA was combined with AFM in 2011 to allow the identification of different proteins ${ }^{112}$ in multiprotein complexes. In the same year, the Moerner laboratory combined blink microscopy with AFM to demonstrate single molecule sub-diffraction fluorescence examination of amyloid disease protein aggregates, ${ }^{113}$ which are an interesting species due to their intricate nanostructures in vitro and sub-diffraction widths. The authors first performed SMLM with ATTO655 maleimide (ATTO-TEC) achieving $48 \mathrm{~nm}$ average localization precision, and then validated the resulting structures with AFM imaging of the same region by using gold alignment marks. In 2013, the first combination of dSTORM and AFM was applied to unveil cell-wall elongation in rod-shaped Gram-negative bacteria. ${ }^{114}$ Using AFM in the tapping mode imaging and dSTORM, the authors proposed a new model of growth for Escherichia coli (E. coli). STORM was performed to accurately assess the nascent peptidoglycan insertion pattern. The authors' system with a $\sim 40 \mathrm{~nm}$ resolution shows that E. coli (MG1655) sacculi and Caulobacter crescentus (NA 1000) sacculi have a discontinuous, patchy synthesis pattern with multiple distinct foci of nascent peptido- 
glycan insertion, from single motifs through to $\sim 50 \mathrm{~nm}$ clusters.

In an early technical note, Hermsdörfer et al. (2013) discussed the integration of AFM/STORM to study fluorescently labelled fixed human cervical cancer cells (HeLa cells). ${ }^{84}$ The microtubules in HeLa cells were labelled with Alexa647 via immuno-fluorescence staining. The combination of the two microscopy techniques provided information of the cell surface appearance with respect to the microtubules and their distribution: 3D STORM gave information about the distribution and structure of individual microtubules in a $z$-range of around $800 \mathrm{~nm}$ with an axial resolution of around 50-75 nm, while AFM yielded topographical and biophysical information.

In the same year Diaspro's laboratory employed AFM/ STORM to image cytoskeletal structures (e.g. microtubule filaments) in HeLa and fibroblast cells. ${ }^{85}$ For STORM experiments, $\alpha$-tubulin in the cells was immunostained with Alexa647, showing a drastic resolution increase when compared to the wide-field image, and allowing precise localization of microtubules in all three dimensions. Tubulin was chosen to give a comparison with correlative AFM/STED images presented in the same manuscript.

In 2014, the laboratory of Cristina Flors presented a new correlative microscopy tool that combined in situ AFM and SMLM microscopy. This novel hybrid system was able to reveal artefacts in SR imaging related to labelling and image reconstruction. ${ }^{115}$ The authors used stretched $\lambda$-DNA labelled with the intercalating cyanine dye YOYO-1, which blinks in the presence of a GLOX buffer containing a reducing thiol compound, ${ }^{116}$ and found out that although most of the $\lambda$-DNA seen in the AFM image appears also in the SR image, there are patchy sections. The authors suggested that this could be related to incomplete labelling, rapid photo-bleaching of YOYO-1 in that region, or poor signal-to-noise ratio leading to exclusion during image analysis. ${ }^{115}$ In 2017 , the same group pioneered a hybrid system combining AFM and two-colour SR fluorescence imaging of $\beta$-lactoglobulin amyloid-like fibrils functionalized with organic fluorophores and quantum dots. ${ }^{117}$ The AFM topography image provided information on the number of filaments that composed the amyloid-like fibrils, while the SR image provided the identification of emissive and non-emissive quantum dots, which allowed differentiating between real localizations in the SR image and spurious ones. Recently a similar method has been used with a dualcolour probe for correlative AFM and SR imaging of polymer fibroid micelles. ${ }^{118}$

In 2015, Georg Fantner's laboratory showed the capabilities of combining AFM/STORM for quantifying the density of localization of F-actin cytoskeletal filaments along cells' 3D topography. ${ }^{86}$ The authors correlated the height and location of actin filaments obtained with an AFM and fluorescence data obtained with STORM. The results revealed that: (1) in areas with one filament (topographical data derived from AFM) labelling fluctuations are attributed to insufficient binding of tagged phalloidin and (2) in areas where AFM revealed two or three filaments the labelling fluctuations originate partially from their presence and not necessarily from insufficient labelling. The authors also suggested that the localization intensity can eventually be used for quantifying the number of actin filaments in a bundle, where AFM information cannot be obtained. In the same work ${ }^{86}$ the authors pioneered the combination of AFM with PALM by expressing the fusion protein RNP-mEos2 in chemically fixed E. coli and live CHO-K1 cells. The use of photoswitchable proteins, i.e. the PALM technique, instead of the toxic dyes and high intensity illumination required for STORM enabled the first demonstration of combined AFM and SR imaging in living cells.

When combining AFM and STORM, AFM imaging is usually performed first before the addition of the STORM buffer, ${ }^{86,115-117}$ because a STORM buffer containing an enzymatic oxygen scavenger is not compatible with AFM imaging. To overcome this limitation Hirvonen et al. replaced the Alexa647 dye by a structurally similar cyanine dye called iFluor647, ${ }^{119}$ which exhibits excellent fluorescence and blinking properties in a buffer that contains a thiol, but no enzymatic oxygen scavenger. ${ }^{120}$ The authors demonstrated that the results obtained with AFM/STORM are independent of which technique is acquired first: the AFM laser with a wavelength of $850 \mathrm{~nm}$ did not have a significant impact in bleaching iFluor647, and there was no evidence of sample damage caused by the STORM laser. They also demonstrated that imaging could be performed for more than $5 \mathrm{~h}$ after the addition of the thiol-only buffer, unlike a traditional STORM buffer where the oxygen scavenger induces a $\mathrm{pH}$ change that degrades the sample and limits the imaging time to a couple of hours. This work was recently extended to demonstrate 2-colour localization microscopy and AFM imaging of podosomes in THP-1 cells. ${ }^{121}$ Two-colour SR images were acquired by combining the STORM imaging of iFluor647-labelled actin with PALM imaging of mEOS3.2-labelled talin, and the authors were able to correlate the podosomes seen in the SR images with higher stiffness areas in AFM images; see Fig. 2.

In addition to the systems described above, the combination of AFM and ASTORM has been recently extended to other biological topics such as the study of virus-host interactions ${ }^{122}$ and membrane proteins. ${ }^{123}$

\subsection{AFM and stimulated emission depletion (STED)}

a. STED technical features. Unlike SMLM where the whole field of view is illuminated at once and the image is captured with a camera, STED uses a focused laser beam that is scanned across the sample, like a confocal microscope. A doughnut-shape depletion beam is then added around the excitation laser, which suppresses spontaneous emission at the periphery of the focal spot by stimulated emission such that fluorescence is allowed at the focal point, but not in its proximity. This leads to an effective fluorescing spot that is smaller than the diffraction limit, and consequently to improved spatial resolution. ${ }^{83}$ The image resolution depends mainly on the laser intensity, and is typically in the range of a 
(a)

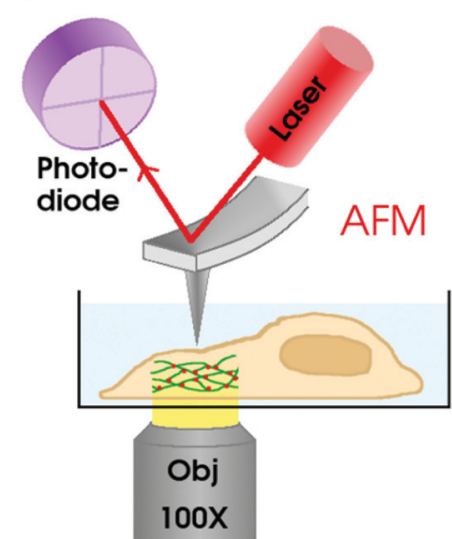

few tens of nanometres with biological samples. Unlike other super-resolution techniques, STED does not require mathematical reconstruction of the final high-resolution image.

b. Correlative AFM and STED. The first combination of AFM and STED was presented in 2012 by the Diaspro laboratory, ${ }^{83}$ who aimed at demonstrating targeted nanomanipulation and force maps in Regions Of Interest (ROIs) in a single cell. As a proof of concept, the authors used fluorescent spheres with $40 \mathrm{~nm}$ diameter and compared the results obtained with the confocal and the AFM/STED hybrid system. They demonstrated that confocal mode, as expected, fails to identify single and agglomerated structures. They expanded the test to study microtubules, an important cytoskeleton component, of fixed Cos7 cells tagged with the label ATTO647N; see Fig. 3(a-f). By combining AFM with STED, it was possible to select a ROI in the super-resolution fluorescence map acquired with STED and perform mapping of force-distance curves with the AFM allowing the determination of local variation of cell stiffness. This also reduced the overall sample investigation time and possible tip contamination due to imprecise targeting. One year later, the authors further developed this work with a study of cytoskeletal structures. ${ }^{124}$ (b)

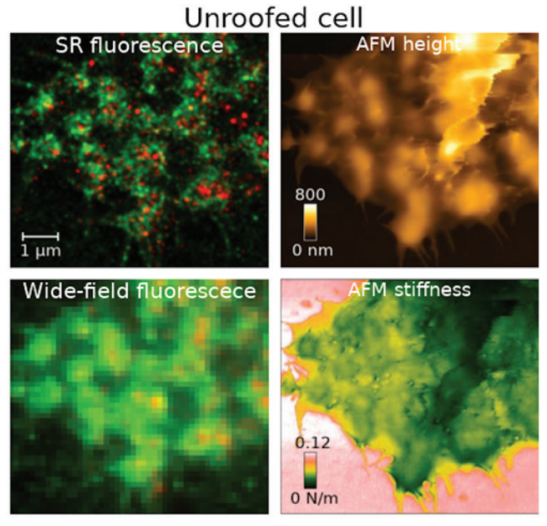

(c)

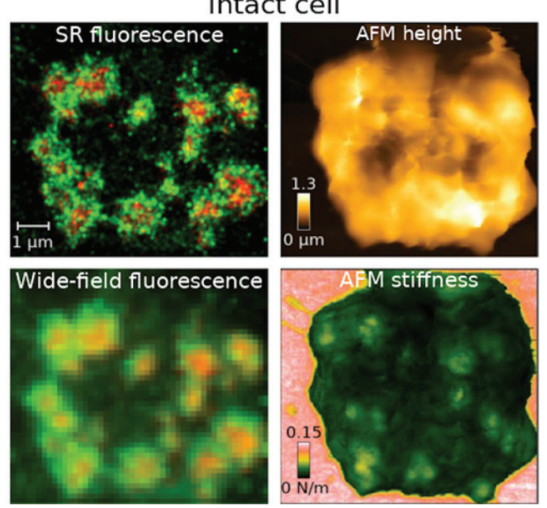

Fig. 2 (a) A schematic diagram of a combined AFM + STORM microscope set-up, where an AFM collects an image of the sample from top, and ed fluorescence set-up. (b and c) Combined fluorescence and AFM images of podosomes in an (b) unroofed and (c) intact THP-1 cell. In the (b) unroofed cell, podosome cores can be seen as higher areas in the AFM height and (c) intact cell, the podosomes are difficult to see in the AFM height image due to a fluffy membrane, but the stiffness image clearly shows podosome cores as stiffer areas under the membrane. Modified from ref. 121 with permission.

Yu et al. reported the integration of AFM and STED using a super-continuum fibre laser and a lateral resolution of $42 \mathrm{~nm} .{ }^{125}$ The super-continuum laser source was used to provide both excitation and STED beams with an energy level higher than $1 \mathrm{~nJ} \mathrm{~nm}^{-1}$. The authors achieved temporal synchronization between the two techniques and tested their system with nanobeads and human cervical carcinoma cells (CaSki cells) where the actin filaments were labelled with phalloidin-ATTO655.

In 2014, Diaspro's laboratory pioneered the manipulation of cells using AFM/STED. ${ }^{126}$ In this proof of principle work, the authors used the AFM tip to manipulate microtubules labelled with Abberior Star 635P inside fixed cells. The results show that in areas where extremely high force was applied with the AFM tip there is a resolution enhancement of the microtubule in the STED image, corresponding to the stretching of a single microtubule in the bundle. In another proof of principle experiment, the authors used the AFM tip to cut a single microtubule filament in a bundle with the help of the STED image.

The combination of AFM and STED was first applied to live cell imaging in 2017. ${ }^{127}$ The authors used correlative microscopy to simultaneously investigate the contribution of 

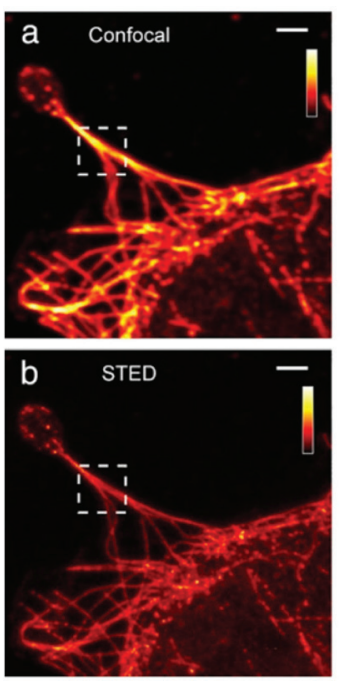

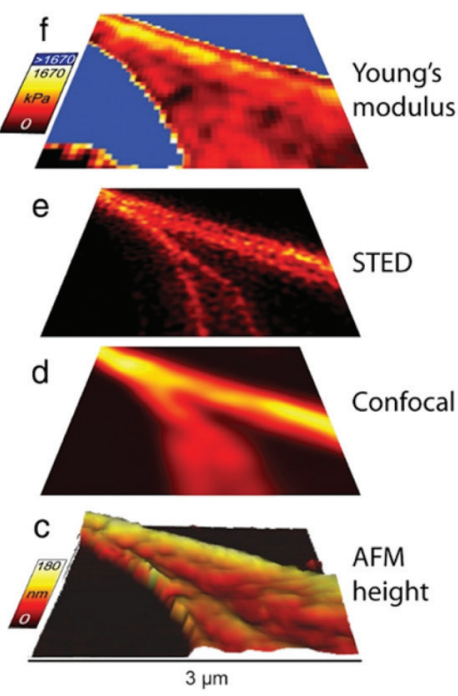

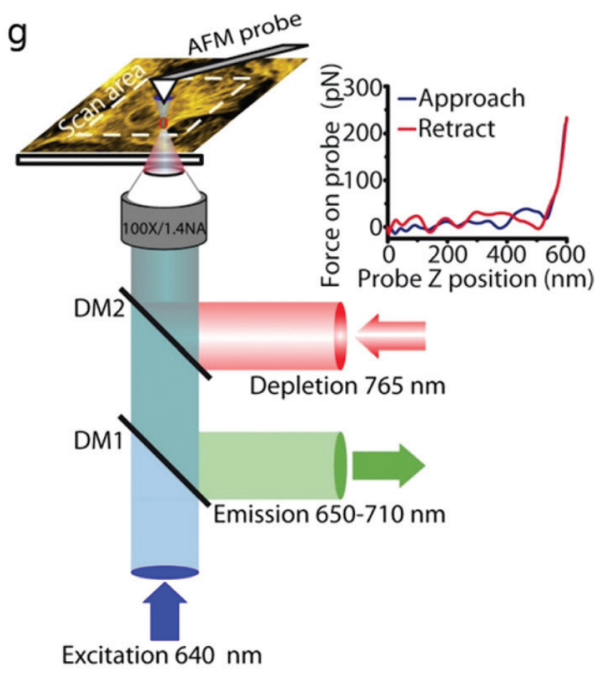

Fig. 3 (a-f) Correlative AFM + STED imaging of Cos7 cells labelled with Atto 647 N. (a) Confocal raw image, (b) STED raw image, (c) 3D rendered view of AFM measured height extracted from AFM force curves, deconvolved (d) confocal and (e) STED images, and ( $f$ ) an elasticity map calculated from AFM force curves. (g) Schematic diagram of a combined AFM/STED imaging set-up. The AFM cantilever is aligned such that STED and AFM have a common scan area. Fluorescence excitation pulses are combined with depletion pulses using a dichroic mirror (DM2), and fluorescent emission is separated using a dichroic mirror (DM1). AFM images are acquired by translating the sample. For each pixel a force curve is measured by approaching the tip toward the sample and recording the tip-sample interaction force as a function of the cantilever $z$-position (see inset), and the Young's modulus is estimated from the gradient. Scale bars in ( $a$ and b): $2 \mu \mathrm{m}$. (a-f) Reproduced from ref. 83 with permission, (g) reproduced from ref. 127 with permission.

fine cytoskeletal elements (actin and tubulin) in astrocyte subcellular compartments, and assessed their involvement in cell topography and mechanical properties under nearly physiological conditions or during polarized migration in vitro. For STED imaging, the authors used a previously described set-up, ${ }^{128}$ see Fig. $3(\mathrm{~g})$, and labelled the cells with SiR-actin and SiRtubulin. ${ }^{129}$ The authors chose actin and tubulin because these cytoskeletal elements are among the very few proteins that can be visualized with STED imaging with a resolution down to $50 \mathrm{~nm}$. In addition, these can be manipulated by pharmacological agents, e.g. nocodazole, that disrupt their assembly. The authors found that the actin networks are highly organized in astrocytes, in those featuring polarization, and that these networks are well reflected in cell topography and are key determinants of membrane stiffness. They also found that tubulin patterns differ from actin patterns in astrocytes, tubulin displays a non-polarized structure in control conditions, and tubulin does not contribute significantly to astrocyte stiffness.

In 2019, Diaspro's laboratory used correlative AFM/STED microscopy to assess the effect of fluorescence labelling on molecular activity. ${ }^{130}$ They studied the in vitro aggregation of insulin from bovine pancreas covalently labelled with $N$-hydroxysuccinimide dye with two alloforms of $\mathrm{A} \beta$ amyloid peptides $\left(A \beta_{1-42}\right.$ and $\left.A \beta_{1-40}\right)$ at different dye-to-protein ratios, and concluded that dye-labelled proteins do not form aggregates as readily as non-labelled proteins, and that STED alone is not capable of characterising all products derived from the in vitro aggregation of misfolded proteins. They also highlighted that AFM can identify fibrillary aggregates that were not shown in the fluorescence microscopy images.
In the same year, AFM/STED was employed to characterise the density and function of actin clusters in neurofibromatosis type 1 , opening the path to suggest a novel actomyosin-dependent mechanism during osteoclast migration and resorption. ${ }^{131}$ Based on the data obtained with correlative microscopy, the authors also demonstrated the timescale of the substrate-specific signalling through which osteoclasts adapt to and polarize towards bone. They also showed differences in actin structures of neurofibromatosis type 1 osteoclast that follow the hyperphosphorylation of cofilin.

\subsection{AFM and super-resolved structured illumination microscopy (SR-SIM)}

a. SR-SIM technical features. In SR-SIM, a fluorescent sample is illuminated with a high-frequency sinusoidal striped pattern of excitation light. These patterns can be generated either by a projection of a physical grid pattern, or with electronic devices, such as spatial light modulators, ${ }^{132-134}$ or digital mirror devices. ${ }^{135-138}$ Multiplication of the sample structure with the illumination pattern generates interference patterns in form of Moiré fringes that contain information about the fine details of the sample structure that could not be observed in diffraction-limited imaging. A series of images is acquired with different pattern positions and orientations, and computational techniques are then applied to remove the illumination structure and retrieve high-resolution information. Although several images, typically 9-15 per optical slice, are required for image reconstruction, SR-SIM is fast compared to SMLM where thousands of frames are required for the final 
image. In SR-SIM, resolution improvement is limited to a factor of two, or a typical resolution of about $120 \mathrm{~nm}$.

b. Correlative AFM and SR-SIM. A combined AFM/SR-SIM microscopy platform capable of achieving simultaneous colocalized imaging of spatially correlated far-field super-resolution fluorescence microscopy and AFM was recently reported by Gómez-Varela et al. ${ }^{87}$ In this hybrid AFM/SR-SIM system, structured illumination is created using three-dimensional SIM (3D-SIM). Here, an additional twofold increase in the axial resolution can be achieved by generating an excitation light modulation along the $z$-axis using three-beam interference. $^{139,140}$ To demonstrate the capability of simultaneous image acquisition, the authors used as a test sample fixed CRISPR/Cas9 genome-edited cells expressing a fluorescently tagged plasma membrane transporter from their genome loci. By performing different AFM measurements with and without the SR-SIM illumination, the authors observed that there is no significant difference in the noise response when the SR-SIM illumination is in place, which would affect the evaluation of individual structures on the cell surface (Fig. 4a-c).

The type of cantilever used in this work, qp-bioAC-CI, has only a limited partial Au coating in order to avoid uncontrolled and disruptive cantilever deflection due to fluorescence excitation light absorption. A schematic drawing of the sample area of this set-up is shown in Fig. $4 d$.

\section{AFM and near-field super- resolution microscopy techniques}

In this section we focus on the near-field techniques combined with AFM: Total Internal Reflection Fluorescence Microscopy (TIRFM) and Scanning Near-Field Optical Microscopy (SNOM).

\subsection{AFM and total internal reflection fluorescence microscopy}

a. TIRFM technical features. Total internal reflection fluorescence microscopy is a near-field microscopy approach based on the phenomenon of total reflection of light happening at highly inclined angles at the glass-medium interface for the illumination of fluorophores. ${ }^{141-143}$ The originating evanescent wave selectively excites the fluorophores in a region restricted to over 100-200 $\mathrm{nm}$ behind the glass surface. TIRFM offers several advantages such as a high signal-to-noise ratio compared to conventional epifluorescence microscopy, ${ }^{144,145}$ there is effectively no out-of-focus fluorescence excitation, and cells are exposed to low light powers. In TIRFM only the axial resolution is enhanced to below the diffraction limit down to $100 \mathrm{~nm}$, which can further be boosted down to $20 \mathrm{~nm}$ by multiangle $^{146}$ or multiwavelength techniques. However, improvement of lateral spatial resolution to $115 \mathrm{~nm}$ has been achieved via the combination of TIRFM and instant Structured Illumination Microscopy (iSIM). ${ }^{147}$

b. Correlative AFM and TIRFM. TIRFM has been combined with AFM for correlating specific components at the interface with the topographical data provided by the AFM. ${ }^{148,149}$ In 2009, Brown et al. applied correlated AFM/TIFRM to investigate self-assembled myosin filaments, which were shown to be asymmetric in physiological buffer. ${ }^{150}$ Authors confirmed that the heads of myosin filaments are arranged in a shell of roughly constant thickness around the filament, consistent with having the heads exposed to the outside as required for their actin-binding function. Furthermore, they used the structural information acquired by AFM of myosin filaments to quantify the fractional asymmetry of synthetic filaments. The combination of TIRFM and time-lapse AFM has also been used to visualize initial stages of fibronectin (FN) fibrillogenesis in living rat embryonic fibroblasts (ref. 52) at high resolu-
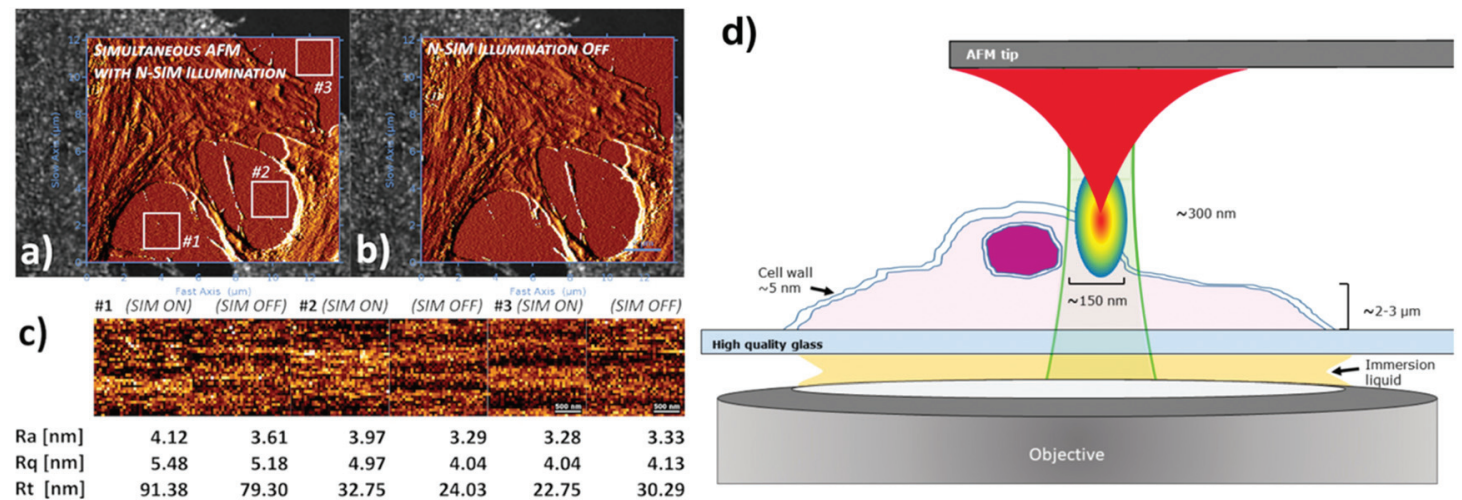

Fig. 4 AFM measurements on fixed U2Os cells in medium/buffer with (a) and without N-SIM illumination (b). For enhanced feature/noise contrast, both AFM topography images in the AFM/SR-SIM overlays are displayed with an edge detection algorithm using a pixel difference operator in X. The topography images from a Petri dish surface on three positions (labelled in the figures) were plane fitted (first order polynomial function) to compensate for tilts in the sample surface, and subjected to surface roughness analysis (c). For comparison reasons, the average roughness $\left(R_{\mathrm{a}}\right)$, RMS roughness $\left(R_{\mathrm{q}}\right)$ and peak-to-valley roughness $\left(R_{\mathrm{t}}\right)$ values are given below the corresponding height profiles. XY-scales of the AFM images in ( $a$ and b) are $13.59 \mu \mathrm{m}$ and $12.16 \mu \mathrm{m}$ respectively, recorded at a resolution of $256 \times 229$ pixels. The insets used for analysis in (c) have a resolution of $37 \times 37$ pixels. (d) Simplified schematic diagram of AFM/SR-SIM imaging conditions within the sample region. Modified from ref. 87 with permission. 
tion. ${ }^{151}$ In this work, the authors correlated the arrangement of fibrillar FN and cellular structures in the light microscopy images with the AFM height information to obtain the structural information of fibronectin. Using time-lapse AFM and based on the fibronectin structure they observed FN fibrillogenesis. They also concluded that when in the presence of $\mathrm{Mn}^{2+}$, fibrillogenesis was promoted and fibrillar dimensions were increased. Oreopoulos et al. reported the design and implementation of a combinatorial microscopy platform integrating polarized TIRFM (pTIRFM) with AFM. Such a system allowed mapping local variations in fluorescent probe orientational order inferred with pTIRFM against topographical features observed using AFM. ${ }^{152,153}$

The versatility of AFM/TIRFM systems for recognition and simultaneous localization of different fluorescent-tagged proteins interacting with DNA has been shown in the last few years. ${ }^{112,154-156}$ A common challenge in hybrid microscopes, is the registration of different types of data. When imaging single molecules the challenge is amplified by the requirement of nanometer precision for localization. The use of fluorescent fiducials for image registration has been shown invaluable, ${ }^{112,157,158}$ and after the development and validation of software routines for consistent, accurate and convenient image registration, AFM/TIRFM systems can be used in a routine manner. ${ }^{155,156,159-161}$ These tools have helped researchers to understand mechanistic aspect of the cellular DNA repair systems, like Homologous Recombination (HR), that efficiently restore genome integrity in healthy cells. ${ }^{162}$ Mutations that affect the function of DNA repair proteins induce cancer and by capturing pictures of these proteins with DNA, how they work can be investigated. HR is a DNA rearrangement where protein recombinases, like RAD51, make filaments with the damaged DNA assisted by BRCA2, a tumour suppressor protein, and RAD54, a motor protein. ${ }^{163}$ To determine the mechanisms of how these mediators influence RAD51 activity, the arrangement of the proteins in complex with DNA has been resolved, demonstrating that different localization of RAD54 on the filaments (terminal or interspersed) promotes different functions, ${ }^{155}$ and how BRCA2 facilitates loading of the repair factor RAD51 by dynamic structural transitions of the complexes. ${ }^{156}$

Correlative AFM/TIRFM schemes often take advantage of AFM force measurement capability to examine sub-cellular variations when mechanical forces are applied. ${ }^{148,149}$ AFM micro- and nano-manipulation capabilities have also been exploited with such hybrid microscopy systems. ${ }^{164,165}$ Mathur et al. described a combination of AFM and TIRFM designed to provide simultaneous mechanical force transmission measurements and focal contact dynamics in human umbilical vein endothelial cells (HUVECs). ${ }^{166}$ TIRFM excites fluorescence in the basal membrane of cells attached to the waveguide surface, while an AFM tip introduced from above the coverslip probes the apical membrane of the same cells. The authors observed that the precise localized mechanical perturbations induced by the AFM tip resulted in a global rearrangement of focal contacts at the basal membrane. In 2002, Nishida et al. reported the combination of AFM with a TIRFM set-up for nanomanipulation of single cells, ${ }^{164}$ describing the delivery of small macromolecules into live cells while simultaneously monitoring with TIRFM the dynamics of these molecules inside the cells. Kellermayer et al. demonstrated in 2006 an AFM/TIRFM system capable of simultaneous spatial and temporal operation. ${ }^{165}$ With this synchronized AFM/TIRFM it is possible to correlate topography and fluorescence features of the examined specimen to mechanically manipulate soft biomolecular samples in a targeted fashion. Furthermore, it allows the monitoring of changes in the fluorescence properties of mechanically stretched biomolecules with high temporal resolution. Because of the spatial synchrony provided by the combined system, the authors were capable of imaging the specimen with scanning TIRFM, subsequently manipulating the same at specific positions with AFM via nanolithography, and finally reimaging the sample with TIRFM to detect the changes. Furthermore, they applied this method to show the ablation of parts of cells and individual actin filaments. A microscopy platform integrating AFM, TIRFM and fast-spinning disk (FSD) confocal microscopy for real-time mechanotransduction studies in live cells was later presented by Trache and Lim. ${ }^{167}$ With this system they later studied the response of vascular smooth muscle cells (VSMCs) to mechanical stimulation using a functionalised AFM tip with extracellular matrix (ECM) proteins laminin or fibronectin, finding that the VSMCadaptive response is adapted to the applied tensile stress and modulated by the pre-existing cytoskeletal tension. ${ }^{168}$ An interesting study by Christenson et al. ${ }^{169}$ described a novel method based on the combination of single cell manipulation by AFM, TIRFM and microcontact printing ${ }^{170}$ to study the stability of multilayer fibrinogen matrices. In order to better understand how the DNA genome is released from the adenovirus during mechanical disassembly, Ortega-Esteban et al. triggered the disruption of single human adenovirus capsids with AFM and monitored the genome exposure with a DNA-specific intercalating fluorescent dye (YOYO-1) that could only access the DNA after the capsid had been opened up. ${ }^{171}$ The fluorescent signals from the released virus genomes during AFM manipulation were observed using a TIRFM set-up. Sarkar et al. demonstrated that TIRFM can measure distances in the axial direction perpendicular to the sample substrate with a length and time resolution comparable to that of an AFM. ${ }^{172}$ They made use of the depth-dependent intensity profile of the TIRFgenerated evanescent wave to track sub-nanometer changes in the vertical displacement of fluorescent beads and quantum dots attached to single ubiquitin proteins tethered between a glass surface and an AFM cantilever during forced unfolding experiments.

In 2017, Harris et al. performed experimental measurements of nanomechanical properties of secretory vesicleplasma membrane tethers using a combined AFM force clamp and TIRF microscopy on membrane sheets from PC12 cells expressing the vesicle marker ANF-eGFP. ${ }^{173}$ The length and frequency of tether-unfolding events were measured using the AFM cantilever while TIRFM was used to locate vesicles and track the movement of vesicles attached to the AFM cantilever 
tip within the TIRF evanescent wave. The experiments revealed a distribution of tether extension steps around $\sim 5 \mathrm{~nm}$ consistent with sequential unfolding of helical domains. More recently, mechanisms of intercellular tension involving cytoskeletal proteins, like catenin and vinculin, have been observed in real time by combining AFM and TIRFM. ${ }^{174}$ The authors visualized $\alpha$-catenin stretched using AFM and the simultaneous recruitment of fluorescently labeled vinculins. The work highlights the potential of the hybrid instrument in the field of mechanobiology (Fig. 5).

\subsection{AFM and scanning near-field optical microscopy}

a. SNOM technical features. Another member of the superresolution microscopy family relying on proximal probes is the Scanning Near-field Optical Microscopy (SNOM), ${ }^{175}$ which sometimes is also referred to as Near-field Scanning Optical Microscopy (NSOM). The first applications and experimental results on the use of SNOM were demonstrated in the period
1984-1986. ${ }^{176-178}$ A unique characteristic of SNOM is that it can utilize a number of different types of tips, including metalized AFM tips. ${ }^{179-181}$ These metalized AFM tips can act as optical antennas that generate intense near-field light. SNOM can work using a wide range of signals including fluorescence signals, ${ }^{182}$ Raman scattering, ${ }^{183}$ infrared absorption ${ }^{184}$ and photoluminescence. ${ }^{185}$ SNOM and especially fluorescencebased SNOM are great candidates for use in biological research as the total signal is proportional to the square of electric field enhancement. ${ }^{186}$ Also, coupling of AFM with SNOM allows simultaneous collection of morphological characteristics of the sample from AFM imaging combined with optical and chemical properties observed in the SNOM image. ${ }^{187}$ On the other hand, it has several disadvantages such as slow scanning speed and low near-field intensity in solution.

b. Correlative AFM and SNOM. Although many of the studies that used correlative AFM/SNOM systems have focused on materials science, these instruments have also found some
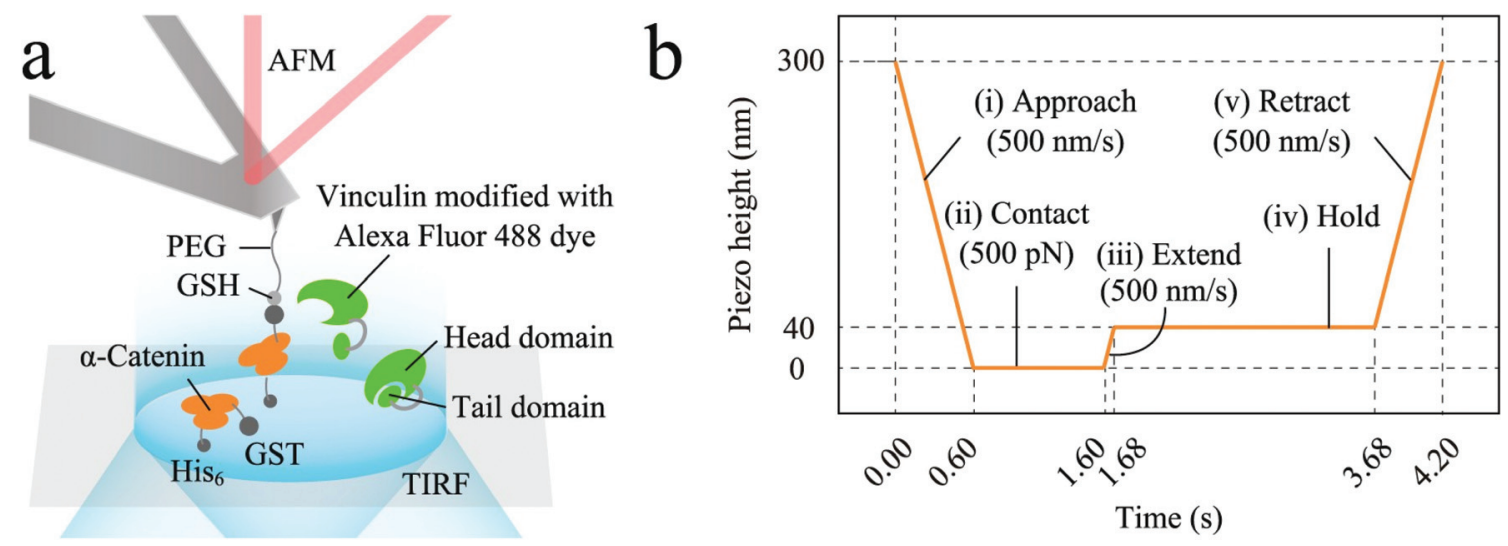

Fig. 5 Example of one of the different AFM/TIFRM combined set-ups reported in the literature. (a) $\alpha$-Catenin molecules (residues 276-634; the mechano-sensitive M1-M3 domain), modified on coverslips, were extended using AFM and simultaneously observed their recruitment of Alexalabelled full-length vinculin molecules, dissolved in solution, using TIRFM; (b) $\alpha$-catenin molecules attached to coverslips were tethered by AFM in programmed piezo-height control phases shown in the figure. Reproduced from ref. 174 with permission.
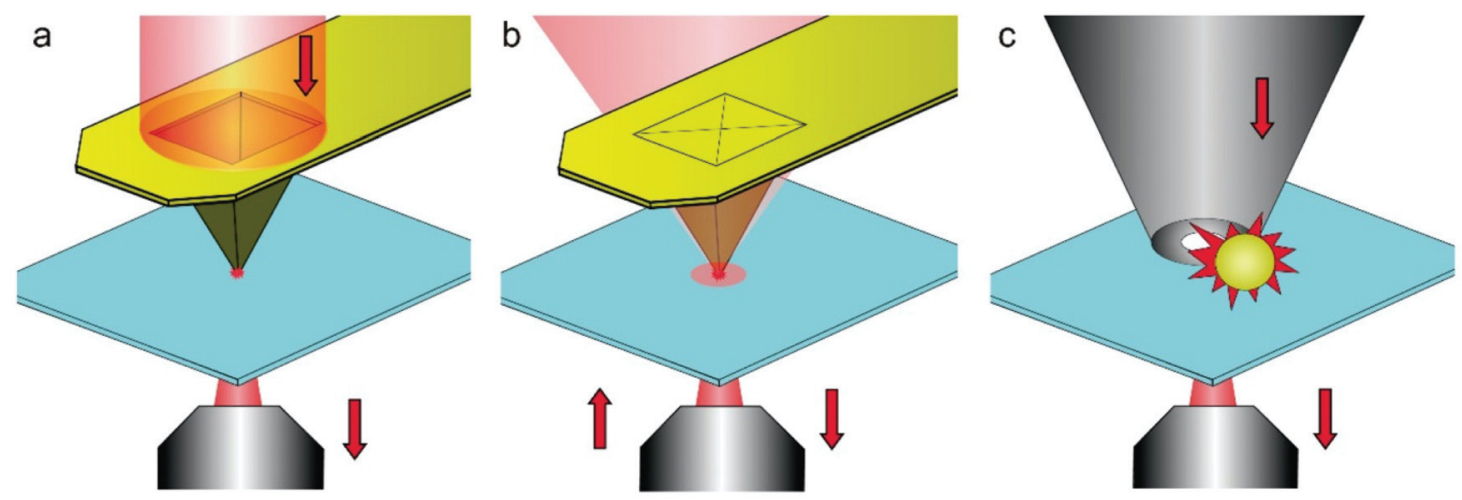

Fig. 6 Various configurations of cantilever based SNOM. (a) Aperture SNOM relying on a specially designed cantilever chip. The tip has a small optical opening at the apex, where a localized evanescent light is produced. (b) Aperture-less SNOM based on a metal-coated cantilever tip that acts as a local electromagnetic antenna (plasmon resonator). (c) SNOM combining a small aperture with an electromagnetic nanoantenna. The nano-antenna is a metal particle with the shape of a bowtie, rod, sphere or dumb-bell aperture-less. Reproduced from ref. 41 with permission. 
applications in the biological sciences. In addition, dried biological specimens, such as single RNA strands and lipid bilayers, were studied with Raman- and infrared vibrational scattering types of SNOM. ${ }^{90,188}$ Recently, Rygula et al. used a commercially available system that combines AFM, SNOM and Raman high-resolution imaging in order to study carotene crystals in a model carrot cell system. ${ }^{189}$ Raman spectroscopy imaging was used to identify different types of crystals, while AFM revealed the crystal topography and SNOM enabled the indication of carotoid-rich structures and their distribution in the cell. Some AFM/NSOM hybrid systems are shown in Fig. 6.

\section{Comparison between correlative microscopy techniques}

Table 1 shows a summary of the hybrid AFM/SR systems described in this manuscript, along with their strengths, limit-

Table 1 Summary of combined AFM/SR systems covered in this review

\begin{tabular}{|c|c|c|c|c|}
\hline & Biological samples & Strengths & Limitations & Ref. \\
\hline $\begin{array}{l}\text { AFM/STORM } \\
\text { and AFM/ } \\
\text { BLINK and } \\
\text { AFM/in situ } \\
\text { SMLM }\end{array}$ & $\begin{array}{l}\text { Fixed Gram-negative bacteria; fixed } \\
\text { HeLa, THP-1 and fibroblast cells; virus- } \\
\text { host interactions; membrane proteins } \\
\text { of human bronchial epithelium; fixed } \\
\text { amyloid disease protein aggregates - } \\
\text { huntingtin proteins; } \lambda \text {-DNA; protein } \\
\text { fibrils }\end{array}$ & $\begin{array}{l}\text { Good fluorescence resolution, } \\
\sim 20-50 \mathrm{~nm} \text { typical; molecular } \\
\text { tracking; AFM can reveal labelling } \\
\text { and image reconstruction } \\
\text { artefacts in SR images }\end{array}$ & $\begin{array}{l}\text { Long image acquisition time; } \\
\text { need to use specific dyes; } \\
\text { staining protocols not } \\
\text { compatible with live cell } \\
\text { imaging; high illumination } \\
\text { intensity required for SMLM; } \\
\text { AFM and GLOX buffer non- } \\
\text { compatibility; not simultaneous }\end{array}$ & $\begin{array}{l}84-86,112, \\
114,115,117 \\
\text { and } 121-123\end{array}$ \\
\hline AFM/PALM & E. coli. CHO-K1 cells & $\begin{array}{l}\text { Good fluorescence resolution, } \\
\sim 20-50 \mathrm{~nm} \text { typical; lower power } \\
\text { laser than STORM; live cell }\end{array}$ & $\begin{array}{l}\text { Long image acquisition time; } \\
\text { need to transfect; not } \\
\text { simultaneous }\end{array}$ & 86 \\
\hline
\end{tabular}

AFM/STED Fixed Cos7 cells; fixed CaSki cells; live astrocytes; bovine insulin from bovine pancreas; alloforms of $\mathrm{A} \beta$ amyloid peptides; neurofibromatosis type 1 osteoclasts

AFM/SR-SIM Gene-edited U2OS cells to expressing MCT1

AFM/TIRFM

$\mathrm{AFM} / \mathrm{SNOM}$
Myosin filaments; fibronectin fibrillogenesis in rat embryonic living fibroblasts (REF52); DOPC/DSPC/ cholesterol model membranes; supported phospholipid bilayers comprised of POPE/TOCL; RNA polymerases (RNAP); BRCA2-RAD51 protein complexes; RAD54 on RAD51ssDNA complexes; living BALB/3T3 cells; HeLa cells and Human pancreatic cancer cells (Panc-1) expressing K8 and K18 keratins; HUVECs; VSMCs; HEK 293 (HEK WT) and HEK 293 cells expressing leukocyte integrin Mac-1ubiquitin protein; PC12 cells expressing the vesicle marker ANF-eGFP; $\alpha$-catenin and vinculin molecules; human fibrinogen; wildtype HAdV-C2 and mutant HAdV-C2_TS1 grown in A549 (human lung carcinoma) and $\mathrm{KB}$ (HeLa-subclone) cells; GroEL, GroES and BSA; chitin crystalline fiber and myosin $\mathrm{V}$ walking on an actin filament; EcoRV-DNA nucleoprotein ensemble Carotene crystal in a model carrot cell system; DNA imaging possible; molecular tracking

Image reconstruction not required; possibility to set common scan area; data shows how fluorophores influence molecular activity

Simultaneous co-localized operation; simple sample preparation protocols; multicolour imaging; live cellimaging: fast image acquisition; low illumination intensity

Fast acquisition time; amenable for simultaneous operation with AFM; selective excitation at interface; low illumination intensity

Simultaneous collection of morphological characteristics of the sample from AFM imaging combined with optical and chemical properties observed in the SNOM image
Not simultaneous; bleaching, specific dyes for STED; need to use fiduciary marks; high illumination intensity

Moderate resolution improvement compared to other SR techniques

Limited to the glass-sample interface

83, 124-127, 130 and 131 87 150-156, 163-169, 171-174, 190 and 191
Slow scanning speed; low nearfield intensity in solution
187,189 and 190 
ations, and biological applications. The SR methods explained in this manuscript have significant differences, but all have become popular methods in biological sciences and have their advantages for specific applications. There is usually a tradeoff between spatial and temporal resolution, and especially with living samples illumination intensity and labelling methods are critical issues. For hybrid AFM/SR systems additional trade-offs need to be considered, such as synchronization of data acquisition, image registration, and spatial overlap of the field of view.

With both SMLM and STED, typical resolution is in the order of few tens of nanometres, the same order of magnitude as the resolution of an AFM when imaging soft biological samples. However, both techniques also usually require high intensity illumination, which interferes with the AFM operation and limits the possibility of simultaneous data acquisition with AFM. As a scanning technique, STED-AFM has the advantage that the STED scan area can be matched with the AFM scan area. This allows the investigation of structures with the same magnification and can help with image correlation. ${ }^{127,129}$

A major limitation in combining AFM and STORM has been the need to change imaging buffers between techniques. Although the frequently used Alexa647 dye has excellent brightness and switching properties in a GLOX buffer, the buffer components crystallise on the AFM cantilever, preventing AFM imaging. As a result, the buffer has to be changed between imaging modes, although recently it has been suggested that this problem can be overcome by replacing Alexa647 by a similar dye iFluor647. ${ }^{120}$ With PALM, the use of photoswitchable proteins instead of dyes solves this problem, but fluorescence labelling requires transfection, which complicates sample preparation. The long image acquisition time of SMLM is also a drawback for imaging living samples.

SR-SIM, on the other hand, uses low illumination intensity, and is therefore well suited for simultaneous data capture with $\mathrm{AFM} ;{ }^{87}$ the main charm of SR-SIM for its integration with AFM relies on a fluorescent excitation light pattern favourable to avoid AFM cantilever disruption during simultaneous operation, and the possibility of live cell imaging. The simultaneous operation of AFM and SR fluorescence techniques has attracted great interest for observations at the nanoscale, and simultaneous operation of AFM and SR-SIM has been recently demonstrated. ${ }^{87}$ SIM data acquisition is also fast compared to other far-field SR methods, which is a significant advantage especially when imaging live samples. However, resolution of the SR-SIM image is limited to $\sim 120 \mathrm{~nm}$, which is substantially above the resolution achievable with AFM.

TIRFM is especially amenable for integration with AFM as the illumination does not interfere with cantilever operation, allowing for imaging biological phenomena at the glasssample interface with high axial resolution. ${ }^{88}$ TIRFM is therefore well suited for applications for surface structures and dynamics located near to the cover glass-sample interface because of the finite penetration depth of the evanescent excitation field (e.g., plasma membrane, cytoskeleton, and ligand- receptor interactions ${ }^{145}$ ). Consequently, it is important to note that its applications are restricted to the bottom cell membrane and it is not suitable for the study of the interior of a cell.

One major challenge in combined AFM/SR is image correlation between the two imaging modes. Different approaches have been used for matching the two images: the use of fiducial markers, ${ }^{113}$ mapping of the AFM tip position with the optical system, ${ }^{115,116}$ and using features that are present in both images. ${ }^{120,129}$ However, there is no standard solution to this problem, and especially with living samples, sample movement between imaging modes or during acquisition adds to the complications. Different fields of view, independent pixel sizes, rotation of the images with respect to each other and sample drift during acquisition all pose significant challenges to image correlation.

As with any hybrid system, a significant challenge for simultaneous AFM/SR data acquisition will be the synchronisation of the different imaging modes. Currently in combined AFM/ SR systems the instruments are operated independently, making it difficult to integrate data acquisition sequences and match the field of view from the two independent instruments. Development of instruments that were designed for hybrid operation would allow seamless synchronisation, for example, between SR illumination and AFM operation, and would also make image correlation easier.

\section{Conclusions and future directions}

Over the past decade, AFM has been combined with a myriad of SR techniques available for unravelling biological enigmas. The SR method of choice critically depends on the biological system under observation, as there are trade-offs to be considered regarding fluorescent labelling, optical resolution in three dimensions, frame recording speed and imaging timeframe. Correlative multimodal systems with AFM and SR techniques offer the possibility to retrieve optical, chemical, and biophysical data from many types of biological samples, such as DNA, proteins or cells. One challenge of hybrid AFM and SR optical systems will be the development of single instruments to simplify data acquisition and control software. Currently, in combined AFM-SR systems the imaging modes are operated independently, and image correlation is performed afterwards.

Hybrid AFM/SR fluorescence systems have been used for the identification of artefacts in the SR images attributed to poor labelling, photobleaching, or image reconstruction issues. AFM data have been used to validate data obtained with SR, for example, to assess the quality of the labelling. AFM has evolved and the data acquisition rates have vastly increased allowing the monitoring of cytoskeletal and cell membrane dynamics on the millisecond to second timescale in living cells. ${ }^{192,193}$ Simultaneous AFM and SR experiments on living cells remain a challenge, mainly due to a variety of technological difficulties such as the use of high-power laser 
sources for SR that interrupt the AFM cantilever operation, the different scan rates of the systems, and the sometimes incompatible imaging buffers. However, SR-SIM is especially amenable to simultaneous data capture with AFM and it has been shown that these two instruments can be operated simultaneously. ${ }^{87}$ This hybrid system is a promising development for the recording of biophysical data and cellular dynamics visualization at the same time. Further resolution improvement can be achieved by Saturated Structured Illumination Microscopy (SSIM), which is based on the nonlinear relationship between the excitation intensity and the emission rate of fluorophores to produce higher order harmonics, further boosting SIM's potential for resolution improvement. Resolution below $50 \mathrm{~nm}$ was demonstrated by Gustafsson et al. in $2005 .{ }^{194}$ One of the drawbacks of SSIM is the high laser power that is required to create the saturation conditions, which - as with SMLM and STED techniques - is likely to disrupt the AFM cantilever operation, and cause photobleaching and damage to living samples.

Recent technological developments are opening new opportunities for correlative SR and AFM imaging adding high temporal resolution by means of high-speed AFM scanners. ${ }^{190,191,195}$ The development of HS-AFM has permitted the simultaneous assessment of structure and dynamics of single proteins during their functional activity. ${ }^{195-198}$ In order to further extend the HS-AFM capabilities, Fukuda et al. presented a combined HS-AFM/TIRFM system and demonstrated simultaneous imaging of linear motions of proteins chitinase A and myosin V. ${ }^{191}$ Later on, simultaneous, correlative tipenhanced TIRFM and HS-AFM imaging of fluorescently labelled protein molecules in solution at relatively high concentration was demonstrated. ${ }^{190}$ Fluorescence enhancement achieved by attaching a single Au particle to the AFM tip is limited to a factor of approximately two due to the distance of the attached $\mathrm{Au}$ particle of about $50 \mathrm{~nm}$ to the tip. This is expected to be improved by modifying the fabrication of the tip so that enough area can be provided for the tip-Au particle contact near the tip end. Even in this new scenario with localized intense light to be achieved after repositioning the $\mathrm{Au}$ particle attachment, photobleaching effects would be reduced compared to conventional TIRFM, as brighter images can be obtained even with lower excitation laser power. In this work the authors go further and show how to achieve higher spatiotemporal resolution with simultaneous high-speed near-field fluorescence microscopy and AFM (HS-SNOM/HS-AFM) by imaging DNA labelled with YOYO-1 in solution. ${ }^{190}$ The authors coated AFM tips with magnetron-sputtered Ag, and achieved a ca. $39 \mathrm{~nm}$ resolution with HS-SNOM and imaging rate of $c a .3$ to $8 \mathrm{~s}$ per frame for SNOM imaging, which is 100 times higher than the typical SNOM imaging rate. This proof of concept is the first step towards further development of the use HS-SNOM on biological studies in combination with HS-AFM.

HS-AFM has significantly decreased AFM data acquisition time, and further improvement to harmonize AFM and the fluorescence data acquisition rate could be achieved by com- bining HS-AFM with an SSIM system. ${ }^{194}$ Another potential pathway consists of combining HS-AFM and video-rate SIM ${ }^{134}$ for living cell studies. The combination of HS-AFM with other far-field SR fluorescence schemes, e.g., STED, is expected to be readily accomplished, although the high illumination intensities required for most SR techniques remain a challenge for simultaneous data collection. In the next decade, we also envisage the consolidation of hybrid systems like HS-AFM/SNOM as well as the appearance of multimodal hybrid systems integrating AFM with two to three microscopy techniques.

\section{Abbreviations}

$\begin{array}{ll}\text { AFM } & \text { Atomic force microscope } \\ \text { CaSki } & \text { Human cervical carcinoma cells } \\ \text { CHO } & \text { Chinese hamster ovarian } \\ \text { COS7 } & \text { CV-1 in origin with SV40 genes African green } \\ & \text { monkey kidney fibroblast } \\ \text { dSTORM } & \text { Direct stochastic optical reconstruction microscopy } \\ \text { E. coli } & \text { Escherichia coli } \\ \text { ECM } & \text { Extracellular matrix } \\ \text { FIONA } & \text { Fluorescence imaging with one nanometer accuracy } \\ \text { FN } & \text { Fibronectin } \\ \text { FWHM } & \text { Full width at half maximum } \\ \text { GLOX } & \text { Glucose oxidase } \\ \text { HeLa } & \text { Human cervical cancer cells } \\ \text { HR } & \text { Homologous recombination } \\ \text { HUVECs } & \text { Human umbilical vein endothelial cells } \\ \text { HS-AFM } & \text { High-speed atomic force microscopy } \\ \text { iSIM } & \text { Instant structured illumination microscopy } \\ \text { PALM } & \text { Photo-activated localization microscopy } \\ \text { pTIRFM } & \text { Polarized TIRFM } \\ \text { ROI } & \text { Region of interest } \\ \text { SIM } & \text { Structured illumination microscopy } \\ \text { SMLM } & \text { Single-molecule localization microscopy } \\ \text { SNOM } & \text { Scanning near-field optical microscopy } \\ \text { SR } & \text { Super-resolution } \\ \text { SSIM } & \text { Saturated structured illumination microscopy } \\ \text { STED } & \text { Stimulated emission depletion } \\ \text { STORM } & \text { Stochastic optical reconstruction microscopy } \\ \text { TIRFM } & \text { Total internal reflection fluorescence microscopy } \\ \text { VSMC } & \text { Vascular smooth muscle cells } \\ \text { YOYO-1 } & \text { Tetracationic homodimer of oxazole yellow } \\ & \\ & \end{array}$

\section{Author contributions}

All authors listed have made substantial, direct, and intellectual contribution to the work, and approved it for publication.

\section{Conflicts of interest}

There are no conflicts to declare. 


\section{Acknowledgements}

Ana I. Gómez Varela acknowledges support from the Xunta de Galicia, Consellería de Cultura, Educación e Ordenación Universitaria e da Consellería de Economía, and Emprego e Industria (Programa de axudas de apoio á etapa de formación posdoutoral 2017). Adelaide Miranda and Pieter De Beule acknowledge financial support from Norte's Regional Operational Programme 2014-2020-Norte2020 (NORTE-1-145FEDER-19). This work was supported by the Fundação para a Ciência e a Tecnologia project SAM - [PTDC/NAN-OPT/31596/ 2017]. Andreas Stylianou acknowledges financial support from the European Research Council and from the University of Cyprus under the projects "CancerFingerPrints" (ERC-2018PoC-838414) and "PacaFingerPrints" (Advanced Post-doctoral Research Fellowship), respectively.

\section{References}

1 G. Binnig, C. F. Quate and C. Gerber, Phys. Rev. Lett., 1986, 56, 930-933.

2 A. L. Weisenhorn, P. Maivald, H.-J. Butt and P. K. Hansma, Phys. Rev. B: Condens. Matter Mater. Phys., 1992, 45, 11226-11232.

3 B. Drake, C. B. Prater, A. L. Weisenhorn, S. A. C. Gould, T. R. Albrecht, C. F. Quate, D. S. Cannell, H. G. Hansma and P. K. Hansma, Science, 1989, 243, 1586-1589.

4 M. Radmacher, R. Tillamnn, M. Fritz and H. Gaub, Science, 1992, 257, 1900-1905.

5 S. M. Lindsay, L. A. Nagahara, T. Thundat, U. Knipping, R. L. Rill, B. Drake, C. B. Prater, A. L. Weisenhorn, S. A. C. Gould and P. K. Hansma, J. Biomol. Struct. Dyn., 1989, 7, 279-287.

6 H. G. Hansma, J. Vesenka, C. Siegerist, G. Kelderman, H. Morrett, R. L. Sinsheimer, V. Elings, C. Bustamante and P. K. Hansma, Science, 1992, 256, 1180-1184.

7 R. D. Edstrom, X. Yang, G. Lee and D. F. Evans, FASEB J., 1990, 4, 3144-3151.

8 A. L. Weisenhorn, B. Drake, C. B. Prater, S. A. Gould, P. K. Hansma, F. Ohnesorge, M. Egger, S. P. Heyn and H. E. Gaub, Biophys. J., 1990, 58, 1251-1258.

9 C. A. Bippes and D. J. Muller, Rep. Prog. Phys., 2011, 74, 086601.

10 N. J. Tao, S. M. Lindsay and S. Lees, Biophys. J., 1992, 63, 1165-1169.

11 M. Kammoun, R. Ternifi, V. Dupres, P. Pouletaut, S. Même, W. Même, F. Szeremeta, J. Landoulsi, J.-M. Constans, F. Lafont, M. Subramaniam, J. R. Hawse and S. F. Bensamoun, Sci. Rep., 2019, 9, 7733.

12 A. J. Malkin, T. A. Land, Y. G. Kuznetsov, A. McPherson and J. J. DeYoreo, Phys. Rev. Lett., 1995, 75, 2778-2781.

13 Y. G. Kuznetsov and A. McPherson, Microbiol. Mol. Biol. Rev., 2011, 75, 268-285.

14 H. Schillers, C. Rianna, J. Schäpe, T. Luque, H. Doschke, M. Wälte, J. J. Uriarte, N. Campillo, G. P. A. Michanetzis,
J. Bobrowska, A. Dumitru, E. T. Herruzo, S. Bovio, P. Parot, M. Galluzzi, A. Podestà, L. Puricelli, S. Scheuring, Y. Missirlis, R. Garcia, M. Odorico, J. M. Teulon, F. Lafont, M. Lekka, F. Rico, A. Rigato, J. L. Pellequer, H. Oberleithner, D. Navajas and M. Radmacher, Sci. Rep., 2017, 7, 5117.

15 A. Stylianou, M. Lekka and T. Stylianopoulos, Nanoscale, 2018, 10, 20930-20945.

16 M. Krieg, G. Fläschner, D. Alsteens, B. M. Gaub, W. H. Roos, G. J. L. Wuite, H. E. Gaub, C. Gerber, Y. F. Dufrêne and D. J. Müller, Nat. Rev. Phys., 2019, 1, 4157.

17 Y. F. Dufrêne, T. Ando, R. Garcia, D. Alsteens, D. MartinezMartin, A. Engel, C. Gerber and D. J. Müller, Nat. Nanotechnol., 2017, 12, 295-307.

18 M. B. Viani, T. E. Schäffer, A. Chand, M. Rief, H. E. Gaub and P. K. Hansma, J. Appl. Phys., 1999, 86, 2258-2262.

19 T. Ando, N. Kodera, E. Takai, D. Maruyama, K. Saito and A. Toda, Proc. Natl. Acad. Sci. U. S. A., 2001, 98, 1246812472.

20 T. Ando, N. Kodera, Y. Naito, T. Kinoshita, K. Furuta and Y. Y. Toyoshima, ChemPhysChem, 2003, 4, 1196-1202.

21 M. Shibata, H. Yamashita, T. Uchihashi, H. Kandori and T. Ando, Nat. Nanotechnol., 2010, 5, 208-212.

22 N. Kodera, D. Yamamoto, R. Ishikawa and T. Ando, Nature, 2010, 468, 72-76.

23 T. Uchihashi, R. Iino, T. Ando and H. Noji, Science, 2011, 333, 755-758.

24 Y. Sakiyama, A. Mazur, L. E. Kapinos and R. Y. H. Lim, Nat. Nanotechnol., 2016, 11, 719-723.

25 G. E. Fantner, R. J. Barbero, D. S. Gray and A. M. Belcher, Nat. Nanotechnol., 2010, 5, 280-285.

26 H. Yamashita, A. Taoka, T. Uchihashi, T. Asano, T. Ando and Y. Fukumori, J. Mol. Biol., 2012, 422, 300-309.

27 M. Shibata, T. Uchihashi, T. Ando and R. Yasuda, Sci. Rep., 2015, 5, 8724.

28 P. Hinterdorfer and Y. F. Dufrêne, Nat. Methods, 2006, 3, 347-355.

29 D. Ristic, H. Sanchez and C. Wyman, in Methods in Molecular Biology, 2011, vol. 783, pp. 213-231.

30 Y. L. Lyubchenko and L. S. Shlyakhtenko, Crit. Rev. Eukaryotic Gene Expression, 2016, 26, 63-96.

31 D. J. Müller, M. Krieg, D. Alsteens and Y. F. Dufrêne, Curr. Opin. Biotechnol., 2009, 20, 4-13.

32 S.-H. Jung, D. Park, J. H. Park, Y.-M. Kim and K.-S. Ha, Exp. Mol. Med., 2010, 42, 597.

33 D. J. Müller and Y. F. Dufrêne, Trends Cell Biol., 2011, 21, 461-469.

34 T. Ando, T. Uchihashi and N. Kodera, Annu. Rev. Biophys., 2013, 42, 393-414.

35 Y. F. Dufrêne, D. Martínez-Martín, I. Medalsy, D. Alsteens and D. J. Müller, Nat. Methods, 2013, 10, 847-854.

36 K. Haase and A. E. Pelling, J. R. Soc., Interface, 2015, 12, 20140970

37 F. A. Carvalho and N. C. Santos, IUBMB Life, 2012, 64, 465-472. 
38 C. Bustamante, D. Keller and G. Yang, Curr. Opin. Struct. Biol., 1993, 3, 363-372.

39 S. Moreno Flores and J. L. Toca-Herrera, Nanoscale, 2009, 1,40 .

40 J. Caplan, M. Niethammer, R. M. Taylor and K. J. Czymmek, Curr. Opin. Struct. Biol., 2011, 21, 686-693.

41 T. Ando, S. P. Bhamidimarri, N. Brending, H. Colin-York, L. Collinson, N. De Jonge, P. J. de Pablo, E. Debroye, C. Eggeling, C. Franck, M. Fritzsche, H. Gerritsen, B. N. G. Giepmans, K. Grunewald, J. Hofkens, J. P. Hoogenboom, K. P. F. Janssen, R. Kaufmann, J. Klumperman, N. Kurniawan, J. Kusch, N. Liv, V. Parekh, D. B. Peckys, F. Rehfeldt, D. C. Reutens, M. B. J. Roeffaers, T. Salditt, I. A. T. Schaap, U. S. Schwarz, P. Verkade, M. W. Vogel, R. Wagner, M. Winterhalter, H. Yuan and G. Zifarelli, J. Phys. D: Appl. Phys., 2018, 51, 443001.

42 A. Walter, P. Paul-Gilloteaux, B. Plochberger, L. Sefc, P. Verkade, J. G. Mannheim, P. Slezak, A. Unterhuber, M. Marchetti-Deschmann, M. Ogris, K. Bühler, D. Fixler, S. H. Geyer, W. J. Weninger, M. Glösmann, S. Handschuh and T. Wanek, Front. Phys., 2020, 8, 47.

43 J. Ma, X. Lv, S. Yang, G. Tian and X. Liu, Microsc. Microanal., 2015, 21, 1304-1313.

44 M. Shemesh, S. Addadi, Y. Milstein, B. Geiger and L. Addadi, ACS Appl. Mater. Interfaces, 2016, 8, 1493214943.

45 G. D. McEwen, Y. Wu, M. Tang, X. Qi, Z. Xiao, S. M. Baker, T. Yu, T. A. Gilbertson, D. B. DeWald and A. Zhou, Analyst, 2013, 138, 787-797.

46 O. Chaudhuri, S. H. Parekh, W. A. Lam and D. A. Fletcher, Nat. Methods, 2009, 6, 383-387.

47 R. Ghosh Chaudhuri and S. Paria, Chem. Rev., 2012, 112, 2373-2433.

48 P. Bondia, J. Torra, C. M. Tone, T. Sawazaki, A. del Valle, B. Sot, S. Nonell, M. Kanai, Y. Sohma and C. Flors, J. Am. Chem. Soc., 2020, 142, 922-930.

49 N. A. Geisse, Mater. Today, 2009, 12, 40-45.

50 A. R. Burns, Langmuir, 2003, 19, 8358-8363.

51 G. Pfister, C. M. Stroh, H. Perschinka, M. Kind, M. Knoflach, P. Hinterdorfer and G. Wick, J. Cell Sci., 2005, 118, 1587-1594.

52 R. Kassies, K. O. van der Werf, A. Lenferink, C. N. Hunter, J. D. Olsen, V. Subramaniam and C. Otto, J. Microsc., 2005, 217, 109-116.

53 Z. Deng, T. Zink, H. Chen, D. Walters, F. Liu and G. Liu, Biophys. J., 2009, 96, 1629-1639.

54 M. Krause, J. te Riet and K. Wolf, Phys. Biol., 2013, 10, 065002.

55 M. S. Kuyukina, I. B. Ivshina, I. O. Korshunova and E. V. Rubtsova, J. Microbiol. Methods, 2014, 107, 23-29.

56 J. R. Staunton, B. L. Doss, S. Lindsay and R. Ros, Sci. Rep., 2016, 6, 19686.

57 S. V. Bhat, T. Sultana, A. Körnig, S. McGrath, Z. Shahina and T. E. S. Dahms, Sci. Rep., 2018, 8, 1-10.

58 A. Trache and S.-M. Lim, J. Visualized Exp., 2010, 4-7.
59 A. Miranda, M. Martins and P. A. A. De Beule, Rev. Sci. Instrum., 2015, 86, 093705.

60 C. C. Moura, A. Miranda, R. O. C. Oreffo and P. A. A. De Beule, Biochem. Biophys. Res. Commun., 2020, 529, 392397.

61 K. Beicker, E. T. O’Brien, M. R. Falvo and R. Superfine, Sci. Rep., 2018, 8, 1504.

62 E. Nelsen, C. M. Hobson, M. E. Kern, J. P. Hsiao, E. T. O'Brien III, T. Watanabe, B. M. Condon, M. Boyce, S. Grinstein, K. M. Hahn, M. R. Falvo and R. Superfine, Sci. Rep., 2020, 10, 8133.

63 C. M. Hobson, M. Kern, E. T. O’Brien, A. D. Stephens, M. R. Falvo and R. Superfine, Mol. Biol. Cell, 2020, 31(16), 1788-1801.

64 S. A. Vickery and R. C. Dunn, J. Microsc., 2001, 202, 408412.

65 M. Micic, D. Hu, Y. D. Suh, G. Newton, M. Romine and H. P. Lu, Colloids Surf., B, 2004, 34, 205-212.

66 S. Chiantia, N. Kahya, J. Ries and P. Schwille, Biophys. J., 2006, 90, 4500-4508.

67 E. Abbe, Arch. Mikrosk. Anat., 1873, 9, 413-468.

68 B. Huang, M. Bates and X. Zhuang, Annu. Rev. Biochem., 2009, 78, 993-1016.

69 L. Schermelleh, R. Heintzmann and H. Leonhardt, J. Cell Biol., 2010, 190, 165-175.

70 A. M. Sydor, K. J. Czymmek, E. M. Puchner and V. Mennella, Trends Cell Biol., 2015, 25, 730-748.

71 G. T. Di Francia, Nuovo Cimento, 1952, 9, 426-438.

72 G. Toraldo di Francia, J. Opt. Soc. Am., 1955, 45, 497.

73 S. W. Hell and J. Wichmann, Opt. Lett., 1994, 19, 780-782.

74 M. Dyba and S. W. Hell, Phys. Rev. Lett., 2002, 88, 163901.

75 V. Westphal, L. Kastrup and S. W. Hell, Appl. Phys. B, 2003, 77, 377-380.

76 M. G. L. Gustafsson, J. Microsc., 2000, 198, 82-87.

77 E. Betzig, Opt. Lett., 1995, 20, 237.

78 M. J. Rust, M. Bates and X. Zhuang, Nat. Methods, 2006, 3, 793-795.

79 E. Betzig, G. H. Patterson, R. Sougrat, O. W. Lindwasser, S. Olenych, J. S. Bonifacino, M. W. Davidson, J. Lippincott-Schwartz and H. F. Hess, Science, 2006, 313, 1642-1645.

80 S. T. Hess, T. P. K. Girirajan and M. D. Mason, Biophys. J., 2006, 91, 4258-4272.

81 H. Miller, Z. Zhou, J. Shepherd, A. J. M. Wollman and M. C. Leake, Rep. Prog. Phys., 2018, 81, 024601.

82 M. Hauser, M. Wojcik, D. Kim, M. Mahmoudi, W. Li and K. Xu, Chem. Rev., 2017, 117, 7428-7456.

83 B. Harke, J. V. Chacko, H. Haschke, C. Canale and A. Diaspro, Opt. Nanosc., 2012, 1, 3.

84 A. Hermsdörfer, J. Madl and W. Römer, Tech. note JPK Instruments AG, Ger., 2013, 1-9.

85 J. V. Chacko, F. C. Zanacchi and A. Diaspro, Cytoskeleton, 2013, 70, 729-740.

86 P. D. Odermatt, A. Shivanandan, H. Deschout, R. Jankele, A. P. Nievergelt, L. Feletti, M. W. Davidson, A. Radenovic and G. E. Fantner, Nano Lett., 2015, 15, 4896-4904. 
87 A. I. Gómez-Varela, D. R. Stamov, A. Miranda, R. Alves, C. Barata-Antunes, D. Dambournet, D. G. Drubin, S. Paiva and P. A. A. De Beule, Sci. Rep., 2020, 10, 1122.

88 J. E. Shaw, J. Oreopoulos, D. Wong, J. C. Y. Hsu and C. M. Yip, Surf. Interface Anal., 2006, 38, 1459-1471.

89 A. Rygula, T. Oleszkiewicz, E. Grzebelus, M. Z. Pacia, M. Baranska and R. Baranski, Spectrochim. Acta, Part A, 2018, 197, 47-55.

90 E. Bailo and V. Deckert, Angew. Chem., Int. Ed., 2008, 47, 1658-1661.

91 R. Garcia and E. T. Herruzo, Nat. Nanotechnol., 2012, 7, 217-226.

92 Z. Al-Rekabi and S. Contera, Proc. Natl. Acad. Sci. U. S. A., 2018, 115, 2658-2663.

93 P. Eaton and P. West, Atomic Force Microscopy, Oxford University Press, 2019.

94 A. Stylianou and D. Yova, Mater. Sci. Eng., C, 2013, 33, 2947-2957.

95 N. Gadegaard, Biotech. Histochem., 2006, 81, 87-97.

96 D. J. Müller, A. C. Dumitru, C. Lo Giudice, H. E. Gaub, P. Hinterdorfer, G. Hummer, J. J. De Yoreo, Y. F. Dufrêne and D. Alsteens, Chem. Rev., 2020, DOI: 10.1021/acs. chemrev.0c00617.

97 H. J. Butt, B. Cappella and M. Kappl, Surf. Sci. Rep., 2005, 59, 1-152.

98 A. Stylianou, V. Gkretsi and T. Stylianopoulos, MethodsX, 2018, 5, 503-513.

99 A. Stylianou, V. Gkretsi, C. S. Patrickios and T. Stylianopoulos, Exploring the nano-surface of collagenous and other fibrotic tissue with AFM, in Fibrosis, ed. S. N. Y. L. Rittié, New York, 2017, pp. 453-489.

100 D. Alsteens, H. E. Gaub, R. Newton, M. Pfreundschuh, C. Gerber and D. J. Müller, Nat. Rev. Mater., 2017, 2, 1-16.

101 S. V. Kontomaris, A. Stylianou, K. S. Nikita, A. Malamou and T. Stylianopoulos, Phys. Biol., 2019, 16, 056003.

102 S. V. Kontomaris, A. Stylianou, K. S. Nikita and A. Malamou, Mater. Res. Express, 2019, 6, 115410.

103 D. J. Müller and Y. F. Dufrêne, Nat. Nanotechnol., 2008, 3, 261-269.

104 S. K. Kufer, E. M. Puchner, H. Gumpp, T. Liedl and H. E. Gaub, Science, 2008, 319, 594-596.

105 A. Yildiz, J. N. Forkey, S. A. McKinney, T. Ha, Y. E. Goldman and P. R. Selvin, Science, 2003, 300, 20612065.

106 M. Heilemann, S. Van De Linde, M. Schüttpelz, R. Kasper, B. Seefeldt, A. Mukherjee, P. Tinnefeld and M. Sauer, Angew. Chem., Int. Ed., 2008, 47, 6172-6176.

107 J. Vogelsang, T. Cordes, C. Forthmann, C. Steinhauer and P. Tinnefeld, Proc. Natl. Acad. Sci. U. S. A., 2009, 106, 8107-8112.

108 T. Cordes, M. Strackharn, S. W. Stahl, W. Summerer, C. Steinhauer, C. Forthmann, E. M. Puchner, J. Vogelsang, H. E. Gaub and P. Tinnefeld, Nano Lett., 2010, 10, 645-651.

109 S. van de Linde, U. Endesfelder, A. Mukherjee, M. Schüttpelz, G. Wiebusch, S. Wolter, M. Heilemann and M. Sauer, Photochem. Photobiol. Sci., 2009, 8, 465.
110 A. Sharonov and R. M. Hochstrasser, Proc. Natl. Acad. Sci. U. S. A., 2006, 103, 18911-18916.

111 R. Jungmann, M. S. Avendaño, J. B. Woehrstein, M. Dai, W. M. Shih and P. Yin, Nat. Methods, 2014, 11, 313318.

112 D. N. Fronczek, C. Quammen, H. Wang, C. Kisker, R. Superfine, R. Taylor, D. A. Erie and I. Tessmer, Ultramicroscopy, 2011, 111, 350-355.

113 W. C. Duim, B. Chen, J. Frydman and W. E. Moerner, ChemPhysChem, 2011, 12, 2387-2390.

114 R. D. Turner, A. F. Hurd, A. Cadby, J. K. Hobbs and S. J. Foster, Nat. Commun., 2013, 4, 1496.

115 A. Monserrate, S. Casado and C. Flors, ChemPhysChem, 2014, 15, 647-650.

116 P. Bondia, S. Casado and C. Flors, in Methods in Molecular Biology, 2017, vol. 1663, pp. 105-113.

117 P. Bondia, R. Jurado, S. Casado, J. M. Domínguez-Vera, N. Gálvez and C. Flors, Small, 2017, 13, 1603784.

118 J. Wang, Z. Wang, Y. Xu, X. Wang, Z. Yang, H. Wang and Z. Tian, Nanoscale, 2020, 12, 17203-17212.

119 L. M. Hirvonen, G. E. Jones and S. Cox, Microsc. Anal., 2018, 32, 17-19.

120 L. M. Hirvonen and S. Cox, Methods Appl. Fluoresc., 2018, 6, 045002 .

121 L. M. Hirvonen, R. J. Marsh, G. E. Jones and S. Cox, Eur. J. Cell Biol., 2020, 99, 151106.

122 S. Dahmane, C. Doucet, A. Le Gall, C. Chamontin, P. Dosset, F. Murcy, L. Fernandez, D. Salas, E. Rubinstein, M. Mougel, M. Nollmann and P.-E. Milhiet, Nanoscale, 2019, 11, 6036-6044.

123 L. Zhou, J. Gao, H. Wang, Y. Shi, H. Xu, Q. Yan, Y. Jing, J. Jiang, M. Cai and H. Wang, Nanoscale, 2020, 12, 99509957.

124 J. V. Chacko, C. Canale, B. Harke and A. Diaspro, PLoS One, 2013, 8, e66608.

125 J. Yu, J. Yuan, X. Zhang, J. Liu and X. Fang, Chin. Sci. Bull., 2013, 58, 4045-4050.

126 J. V. Chacko, B. Harke, C. Canale and A. Diaspro, J. Biomed. Opt., 2014, 19, 105003.

127 N. Curry, G. Ghézali, G. S. Kaminski Schierle, N. Rouach and C. F. Kaminski, Front. Cell. Neurosci., 2017, 11, 104.

128 P. Mahou, N. Curry, D. Pinotsi, G. K. Schierle and C. Kaminski, in Proc. SPIE, 2015, vol. 9331.

129 G. Lukinavičius, L. Reymond, E. D’Este, A. Masharina, F. Göttfert, H. Ta, A. Güther, M. Fournier, S. Rizzo, H. Waldmann, C. Blaukopf, C. Sommer, D. W. Gerlich, H.-D. Arndt, S. W. Hell and K. Johnsson, Nat. Methods, 2014, 11, 731-733.

130 M. Cosentino, C. Canale, P. Bianchini and A. Diaspro, Sci. $A d v .$, 2019, 5, eaav8062.

131 T. Deguchi, E. Fazeli, S. Koho, P. Pennanen, M. Alanne, M. Modi, J. E. Eriksson, K. V. Vienola, P. E. Hänninen, J. Peltonen and T. Näreoja, J. Phys. D: Appl. Phys., 2020, 53, 014003.

132 B.-J. Chang, L.-J. Chou, Y.-C. Chang and S.-Y. Chiang, Opt. Express, 2009, 17, 14710. 
133 L. M. Hirvonen, K. Wicker, O. Mandula and R. Heintzmann, Eur. Biophys. J., 2009, 38, 807-812.

134 A. Markwirth, M. Lachetta, V. Mönkemöller, R. Heintzmann, W. Hübner, T. Huser and M. Müller, Nat. Commun., 2019, 10, 4315.

135 A. Sandmeyer, M. Lachetta, H. Sandmeyer, W. Hübner, T. Huser and M. Müller, bioRxiv, 2019, 797670.

136 P. T. Brown, R. Kruithoff, G. J. Seedorf and D. P. Shepherd, bioRxiv, 2020, 1-12.

137 T. Woo, S. H. Jung, C. Ahn, B. Hwang, H. Kim, J. H. Kang and J.-H. Park, Optica, 2020, 7, 973.

138 M. Lachetta, H. Sandmeyer, A. Sandmeyer, J. Schulte Am Esch, T. Huser and M. Müller, bioRxiv, 2020, 2020.10. 02.323527.

139 M. G. L. Gustafsson, L. Shao, P. M. Carlton, C. J. R. Wang, I. N. Golubovskaya, W. Z. Cande, D. A. Agard and J. W. Sedat, Biophys. J., 2008, 94, 4957-4970.

140 L. Schermelleh, P. M. Carlton, S. Haase, L. Shao, L. Winoto, P. Kner, B. Burke, M. C. Cardoso, D. A. Agard, M. G. L. Gustafsson, H. Leonhardt and J. W. Sedat, Science, 2008, 320, 1332-1336.

141 D. Axelrod, J. Cell Biol., 1981, 89, 141-145.

142 A. L. Mattheyses, S. M. Simon and J. Z. Rappoport, J. Cell Sci., 2010, 123, 3621-3628.

143 E. J. Ambrose, Nature, 1956, 178, 1194-1194.

144 T. Funatsu, Y. Harada, M. Tokunaga, K. Saito and T. Yanagida, Nature, 1995, 374, 555-559.

145 K. N. Fish, Curr. Protoc. Cytom., 2009, 50, 12.18.1-12.18.13.

146 Y. Fu, P. W. Winter, R. Rojas, V. Wang, M. McAuliffe and G. H. Patterson, Proc. Natl. Acad. Sci. U. S. A., 2016, 113, 4368-4373.

147 M. Guo, P. Chandris, J. P. Giannini, A. J. Trexler, R. Fischer, J. Chen, H. D. Vishwasrao, I. Rey-Suarez, Y. Wu, X. Wu, C. M. Waterman, G. H. Patterson, A. Upadhyaya, J. W. Taraska and H. Shroff, Nat. Methods, 2018, 15, 425-428.

148 L. Zhou, M. Cai, T. Tong and H. Wang, Sensors, 2017, 17, 938.

149 S. Handschuh-Wang, T. Wang and X. Zhou, RSC Adv., 2017, 7, 47464-47499.

150 A. E. X. Brown, A. Hategan, D. Safer, Y. E. Goldman and D. E. Discher, Biophys. J., 2009, 96, 1952-1960.

151 T. Gudzenko and C. M. Franz, Mol. Biol. Cell, 2015, 26, 3190-3204.

152 J. Oreopoulos and C. M. Yip, Biophys. J., 2009, 96, 1970-1984.

153 J. Oreopoulos, R. F. Epand, R. M. Epand and C. M. Yip, Biophys. J., 2010, 98, 815-823.

154 Y. Ebenstein, N. Gassman, S. Kim and S. Weiss, in Journal of Molecular Recognition, NIH Public Access, 2009, vol. 22, pp. 397-402.

155 H. Sanchez, A. Kertokalio, S. van Rossum-Fikkert, R. Kanaar and C. Wyman, Proc. Natl. Acad. Sci. U. S. A., 2013, 110, 11385-11390.

156 H. Sánchez, M. W. Paul, M. Grosbart, S. E. Van RossumFikkert, J. H. G. Lebbink, R. Kanaar, A. B. Houtsmuller and C. Wyman, Nucleic Acids Res., 2017, 45, 4507-4518.
157 H. Sanchez, R. Kanaar and C. Wyman, Ultramicroscopy, 2010, 110, 844-851.

158 W. Frederickx, S. Rocha, Y. Fujita, K. Kennes, H. De Keersmaecker, S. De Feyter, H. Uji-I and W. Vanderlinden, ACS Nano, 2018, 12, 168-177.

159 H. Sánchez and C. Wyman, BMC Bioinf., 2015, 16, 27.

160 M. Grosbart, D. Ristić, H. Sánchez and C. Wyman, in Methods in Molecular Biology, Humana Press Inc., 2018, vol. 1665, pp. 259-280.

161 A. Sidhu, D. Ristic, H. Sánchez and C. Wyman, in Methods in Enzymology, Academic Press Inc., 2018, vol. 600, pp. 347-374.

162 H. Sanchez, M. Reuter, M. Yokokawa, K. Takeyasu and C. Wyman, DNA Repair, 2014, 20, 110-118.

163 W. D. Heyer, K. T. Ehmsen and J. Liu, Annu. Rev. Genet., 2010, 44, 113-139.

164 S. Nishida, Y. Funabashi and A. Ikai, Ultramicroscopy, 2002, 91, 269-274.

165 M. S. Z. Kellermayer, Á. Karsai, A. Kengyel, A. Nagy, P. Bianco, T. Huber, Á. Kulcsár, C. Niedetzky, R. Proksch and L. Grama, Biophys. J., 2006, 91, 2665-2677.

166 A. B. Mathur, G. A. Truskey and W. M. Reichert, Biophys. J., 2000, 78, 1725-1735.

167 A. Trache and S.-M. Lim, J. Biomed. Opt., 2009, 14, 034024. 168 S.-M. Lim, J. P. Trzeciakowski, H. Sreenivasappa, L. J. Dangott and A. Trache, Integr. Biol., 2012, 4, 615627.

169 W. Christenson, I. Yermolenko, B. Plochberger, F. Camacho-Alanis, A. Ros, T. P. Ugarova and R. Ros, Ultramicroscopy, 2014, 136, 211-215.

170 A. Kumar and G. M. Whitesides, Appl. Phys. Lett., 1993, 63, 2002-2004.

171 A. Ortega-Esteban, K. Bodensiek, C. San Martín, M. Suomalainen, U. F. Greber, P. J. De Pablo and I. A. T. Schaap, ACS Nano, 2015, 9, 10571-10579.

172 A. Sarkar, R. B. Robertson and J. M. Fernandez, Proc. Natl. Acad. Sci. U. S. A., 2004, 101, 12882-12886.

173 K. Maki, S. W. Han, Y. Hirano, S. Yonemura, T. Hakoshima and T. Adachi, Sci. Rep., 2018, 8, 1575.

174 M. C. Harris, D. Cislo, J. S. Lenz, C. Umbach and M. Lindau, PLoS One, 2017, 12, e0173993.

175 A. Bouhelier, in Reference Module in Materials Science and Materials Engineering, Elsevier, 2016.

176 A. Lewis, M. Isaacson, A. Harootunian and A. Muray, Ultramicroscopy, 1984, 13, 227-231.

177 D. W. Pohl, W. Denk and M. Lanz, Appl. Phys. Lett., 1984, 44, 651-653.

178 E. Betzig, A. Lewis, A. Harootunian, M. Isaacson and E. Kratschmer, Biophys. J., 1986, 49, 269-279.

179 Y. Inouye and S. Kawata, Opt. Lett., 1994, 19, 159-161.

180 F. Zenhausern, M. P. O’Boyle and H. K. Wickramasinghe, Appl. Phys. Lett., 1994, 65, 1623-1625.

181 S. Kawata, Y. Inouye and P. Verma, Nat. Photonics, 2009, 3, 388-394.

182 N. Hayazawa, K. Furusawa, A. Taguchi and S. Kawata, J. Appl. Phys., 2009, 106, 113103. 
183 A. Hartschuh, E. J. Sánchez, X. S. Xie and L. Novotny, Phys. Rev. Lett., 2003, 90, 095503.

184 E. A. Muller, B. Pollard, H. A. Bechtel, P. van Blerkom and M. B. Raschke, Sci. Adv., 2016, 2, e1601006-e1601006.

185 W. Bao, N. J. Borys, C. Ko, J. Suh, W. Fan, A. Thron, Y. Zhang, A. Buyanin, J. Zhang, S. Cabrini, P. D. Ashby, A. Weber-Bargioni, S. Tongay, S. Aloni, D. F. Ogletree, J. Wu, M. B. Salmeron and P. J. Schuck, Nat. Commun., 2015, 6, 7993.

186 V. Subramaniam, A. K. Kirsch and T. M. Jovin, Cell. Mol. Biol., 1998, 44, 689-700.

187 P. Bazylewski, S. Ezugwu and G. Fanchini, Appl. Sci., 2017, 7, 973.

188 S. Berweger, D. M. Nguyen, E. A. Muller, H. A. Bechtel, T. T. Perkins and M. B. Raschke, J. Am. Chem. Soc., 2013, 135, 18292-18295.

189 A. Rygula, T. Oleszkiewicz, E. Grzebelus, M. Z. Pacia, M. Baranska and R. Baranski, Spectrochim. Acta, Part A, 2018, 197, 47-55.
190 T. Umakoshi, S. Fukuda, R. Iino, T. Uchihashi and T. Ando, Biochim. Biophys. Acta, Gen. Subj., 2020, 1864, 129325.

191 S. Fukuda, T. Uchihashi, R. Iino, Y. Okazaki, M. Yoshida, K. Igarashi and T. Ando, Rev. Sci. Instrum., 2013, 84, 073706.

192 T. Uchihashi, H. Watanabe, S. Fukuda, M. Shibata and T. Ando, Ultramicroscopy, 2016, 160, 182-196.

193 M. Shibata, H. Watanabe, T. Uchihashi, T. Ando and R. Yasuda, Biophys. Physicobiol., 2017, 14, 127135.

194 M. G. L. Gustafsson, Proc. Natl. Acad. Sci. U. S. A., 2005, 102, 13081-13086.

195 T. Ando, Biophys. Rev., 2018, 10, 285-292.

196 T. Ando, T. Uchihashi and T. Fukuma, Prog. Surf. Sci., 2008, 83, 337-437.

197 T. Ando, Nanotechnology, 2012, 23, 062001.

198 H. Sanchez, Y. Suzuki, M. Yokokawa, K. Takeyasu and C. Wyman, Integr. Biol., 2011, 3, 1127. 